University of California, Hastings College of the Law UC Hastings Scholarship Repository

Faculty Scholarship

2009

\title{
Probabilities, Planning Failures, and Environmental Law
}

Dave Owen

UC Hastings College of the Law, owendave@uchastings.edu

Follow this and additional works at: http://repository.uchastings.edu/faculty_scholarship

\section{Recommended Citation}

Dave Owen, Probabilities, Planning Failures, and Environmental Law, 84 Tul. L. Rev. 265 (2009).

Available at: http://repository.uchastings.edu/faculty_scholarship/1237

This Article is brought to you for free and open access by UC Hastings Scholarship Repository. It has been accepted for inclusion in Faculty Scholarship by an authorized administrator of UC Hastings Scholarship Repository. For more information, please contact marcusc@uchastings.edu. 


\title{
Probabilities, Planning Failures, and Environmental Law
}

\author{
Dave Owen*
}

Environmental laws often mandate specific environmental outcomes and require agencies to adopt plans designed to achieve those outcomes. But because of pervasive uncertainties, agencies are often unsure if their plans will succeed. Decisionmakers therefore must decide how to balance risks of plan failure against the costs of more cautious regulatory approaches. This Article explores and evaluates legal responses to these dilemmas. I find that environmental statutes and regulations use a patchwork of measures to manage these planning uncertainties. Decisions about planning uncertainty are frequently made on an ad hoc, nontransparent basis, and plans with low success odds are common. That approach is problematic, for it impedes public participation, increases vulnerability to decisionmaking biases, and contributes to regulatory dysfinction. I therefore propose procedural and substantive reforms designed to improve transparency and to reduce the frequency of plan failure.

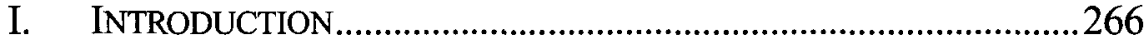

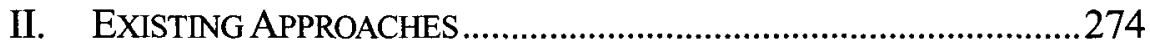

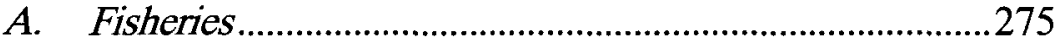

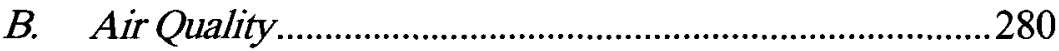

C. Endangered Species .....................................................28

D. National Environmental Policy Act...............................294

E. Water Quality..............................................................299

F. Nuclear Waste................................................................303

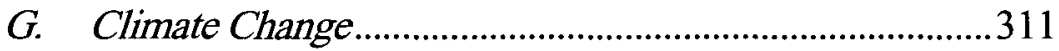

III. REFORMING EXISTING APPROACHES ...................................... 313

A. The Trouble with Ad Hoc Resolutions.............................. 315

1. Transparency .........................................................315

2. Biases and Skewed Outcomes................................. 319

a. Optimism ............................................319

b. Identifiability and Availability ...................322

c. Cumulative Misperceptions........................323

d. Agency Competence and Culture ................326

B. The Benefits of High Probability Standards .....................327

* (C) 2009 Dave Owen. Associate Professor, University of Maine School of Law. I thank Dan Farber, Oliver Houck, Josh Eagle, Jenny Wriggins, Deb Tuerkheimer, and David Cluchey for comments on earlier drafts of this Article. I also thank the members of the Tulane Law Review for their assistance. 


\section{Ex Ante, Ex Post, and the Choice of Reform}

Approaches

IV. CONCLUSION

\section{INTRODUCTION}

Several years ago, management of the summer flounder, a bottomfish inhabiting much of the Atlantic Coast, raised one of environmental law's central dilemmas in particularly distilled form. The National Marine Fisheries Service (NOAA Fisheries) had approved a fishing quota that agency scientists estimated had, at best, an eighteen percent chance of preventing overfishing. 'The Magnuson-Stevens Fishery Conservation and Management $\mathrm{Act}^{2}$ explicitly directs NOAA Fisheries to prevent overfishing, so the quota had at least an eighty-two percent chance of failing to achieve a key statutory mandate. ${ }^{3}$ Environmental groups challenged the quota, and the core legal question in Natural Resources Defense Council, Inc. v. Daley was whether the agency could approve an approach that might work, but was more likely to fail. ${ }^{4}$ Closely related was a second question: if an eighteen percent chance was not good enough, but certainty of success was not achievable unless the entire fishery was shut down, what level of assurance would be sufficient?

Although rarely presented quite so neatly, similar questions pervade environmental law. Environmental law is filled with standards prescribing environmental outcomes and with planning processes intended to achieve those outcomes. ${ }^{5}$ In air and water quality management, ${ }^{6}$ nuclear waste disposal,' fisheries regulation, ${ }^{8}$ and endangered species protection, ${ }^{9}$ among many other areas, ${ }^{10}$ laws use combinations of outcome standards and planning processes. Any major climate change legislation will likely include similar

1. NRDC v. Daley, 209 F.3d 747, 751 (D.C. Cir. 2000).

2. $\quad 16$ U.S.C. $\S \S 1801-1891 \mathrm{c}(2006)$.

3. Daley, 209 F.3d at 754 .

4. The D.C. Circuit's answer was an emphatic no. Id. at 756.

5. See discussion infra Part II. Environmental law, broadly defined as including both pollution control and natural resources law, also contains planning processes designed to identify goals, but my focus here is on plans designed to achieve legally mandated outcomes.

6. See discussion infra Parts II.B, II.E.

7. See discussion infra Part II.F.

8. See discussion infra Part II.A.

9. See discussion infra Part II.C.

10. See discussion infra note 44 . 
approaches." Throughout environmental management, agencies also confront pervasive uncertainties. ${ }^{12}$ Because of these uncertainties, environmental agencies rarely can be certain that their plans will attain statutory goals, unless those plans take extremely intolerant-and therefore, in many circumstances, extremely costly-approaches toward risks of environmental harm. ${ }^{13}$ Using a range of analytical tools, agencies attempt to bound those uncertainties, and they often can estimate the probability of different outcomes. ${ }^{14}$ But unless the agency simply bans environmentally threatening activities, some possibility of plan failure is usually unavoidable. The ubiquitous questions therefore are how much failure risk environmental laws should allow, who should decide, and how those decisions should be made.

Those questions deserve attention from lawmakers. Indeed, related questions have received enormous attention; many of environmental law's most intense battles have addressed the setting of standards for environmental outcomes. ${ }^{15}$ The reasons are straightforward: setting outcome standards implicates basic trade-offs between levels of protection and compliance costs, and these trade-offs are perhaps the most fundamental dilemmas of environmental law. A similar focus on probability standards - that is, standards addressing plans' chances of achieving mandated outcomes - would be equally sensible, because, as Figure 1 illustrates, probability standards are

11. See discussion infra Part II.G.

12. John S. Applegate \& Robert L. Fischman, Foreword Missing Information: The Scientific Data Gap in Conservation and Chemical Regulation, 83 IND. L.J. 399, 399-400 (2008) (describing uncertainty as "one of the obstacles, if not the obstacle, that environmental regulators must overcome in developing sensible and effective laws and policies"); Holly Doremus, Constitutive Law and Environmental Policy, 22 STAN. ENVTL. L.J. 295, 297 (2003) ("Uncertainty pervades every aspect of environmental law.").

Some scholars distinguish between risk, which they define as involving unknown outcomes but known probabilities, and uncertainty, involving unknown probabilities; others describe both situations as varieties of uncertainty. Compare, e.g., Donald T. Hornstein, Reclaiming Environmental Law: A Normative Critique of Comparative Risk Analysis, 92 COLUM. L. REV. 562, 571-72 (1992), with C.S. Holling ET AL., ADAPTIVE ENVIRONMENTAL ASSESSMENT AND MANAGEMENT 133-35 (1978) (using a broader definition). I use the latter definition of uncertainty in this Article, and use risk to refer to the danger that a bad outcome will occur.

13. See generally Cass R. Sunstein, Beyond the Precautionary Principle, 151 U. PA. L. REV. 1003 (2003) (describing the costs of strict precautionary approaches).

14. E.g., NRDC v. Daley, 209 F.3d 747, 750-51 (D.C. Cir. 2000) (describing probability estimates).

15. E.g., Whitman v. Am. Trucking Ass'ns, 531 U.S. 457 (2001) (addressing air quality standards); Nuclear Energy Inst., Inc. v. EPA, 373 F.3d 1251, 1258 (D.C. Cir. 2004) (addressing nuclear waste disposal standards); NRDC v. EPA, 16 F.3d 1395 (4th Cir. 1993) (addressing water quality standards). 
similarly important. A lax probability standard can turn a stringent protection standard into a perpetually unattained aspiration, lowering short-term compliance costs but also creating persistent slippage between legal requirements and actual performance. By contrast, a strict probability standard will usually increase short-term compliance costs, ${ }^{16}$ but it also can reduce the extent of noncompliance and provide greater environmental benefits. Probability standards therefore have substantial environmental and economic implications.

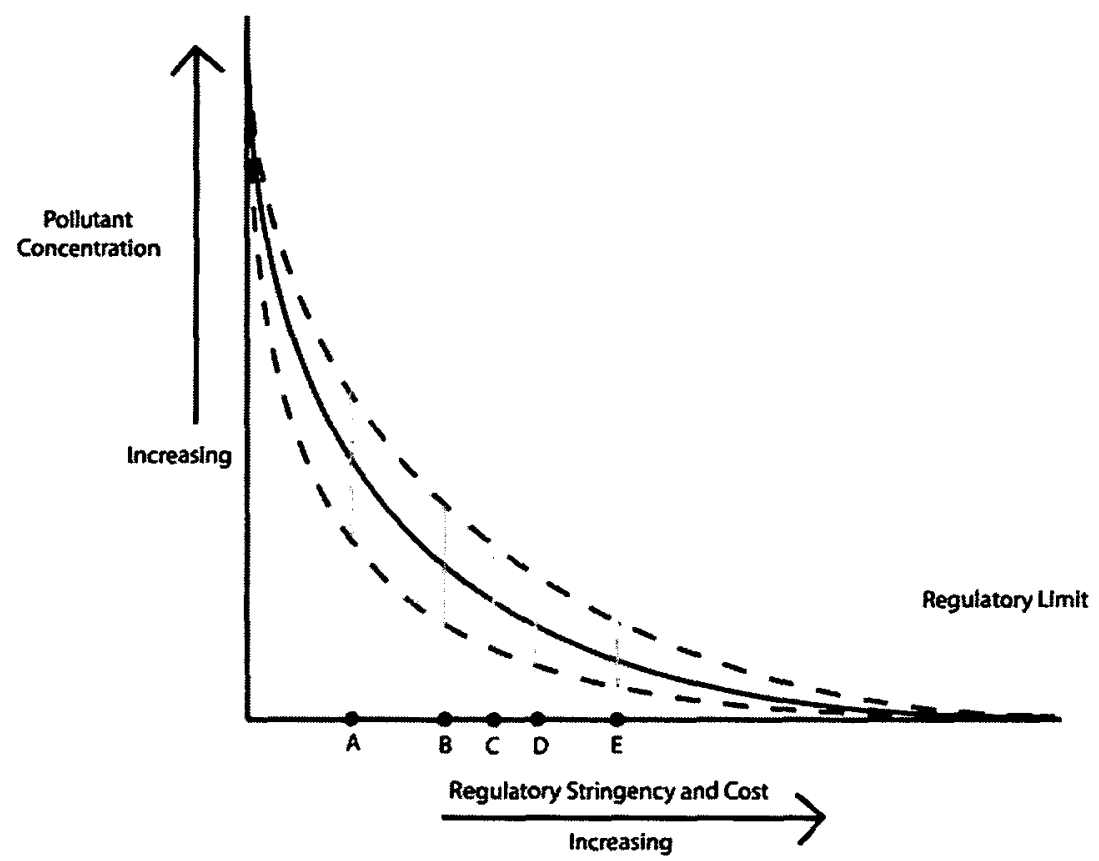

Figure 1: Pollutant concentrations, compliance costs, and bounded uncertainty

This figure illustrates the importance of probability standards. The solid curve shows the mean predicted concentrations of a hypothetical pollutant as a function of regulatory stringency. The dotted lines represent the 5th and 95th percentiles of predicted pollutant concentrations. Points $\mathrm{A}, \mathrm{B}, \mathrm{C}, \mathrm{D}$, and E represent regulatory plans of increasing stringency, with $A$ too lenient to produce compliance, $E$ more stringent than necessary, and $\mathrm{B}, \mathrm{C}$, and $\mathrm{D}$ representing different tradeoffs between the risk of plan failure and potential excess regulatory stringency. The regulatory limit is a numerical limit on the tolerable environmental concentration of the pollutant. The figure illustrates that in contexts of uncertainty, choices about the requisite odds of

16. Such short-term savings may create greater long-term costs, however. See infra notes $342-355$ and accompanying text. 
plan success can significantly influence environmental outcomes and compliance costs. $^{17}$

Yet such attention has been sparse. While a few environmental statutes contain signals about managing plan uncertainty, those signals are often vague or indirect, leaving agencies with minimal guidance and significant amounts of discretion. ${ }^{18}$ Congress has an amply documented track record of underestimating or ignoring environmental uncertainties, ${ }^{19}$ so that inattention is not entirely surprising. But administrative agencies, though theoretically more informed about the uncertainties they must confront, have made few systematic efforts to fill the legislative void. ${ }^{20}$ Rarely have agencies promulgated generally applicable rules setting standards for the probability of plan success. ${ }^{21}$ Nonbinding guidance, though slightly more abundant, has little visibility and often leaves major issues unresolved. ${ }^{22}$ Agency personnel unavoidably address these issues as they develop and approve plans, but they often do so without much evidence of deliberation. ${ }^{23}$ Judicial discussions, while present and even somewhat robust in a few legal contexts, are entirely absent elsewhere, even in circumstances in which planning uncertainty could be a central litigation issue. ${ }^{24}$ Uncertainty management may seem a technically daunting and politically unappealing topic, ${ }^{25}$ and some gap between the

17. The neatness of the curve and the precise prediction of regulatory costs are both unrealistic - though necessary for graphical simplicity-but otherwise Figure 1 depicts common relationships and circumstances. Predictions about plan effectiveness are often uncertain, and efforts to improve environmental outcomes often create exponentially increasing compliance costs.

18. See discussion infra Part II.

19. See Wendy E. Wagner, Congress, Science, and Environmental Policy, 1999 U. ILL. L. REV. $181,184$.

20. See discussion infra Part II.

21. See discussion infra Part II.

22. See discussion infra Part II.

23. See, e.g., discussion infra Part II.B (discussing decisions to approve or reject state implementation plans).

24. See, e.g., infra notes 117-124 and accompanying text (discussing Envtl. Def. v. EPA, 369 F.3d 193 (2d Cir. 2004)).

25. An example from another context illustrates political figures' reluctance to acknowledge uncertainty. In early 2009 , President Obama repeatedly touted the job-creating potential of his recovery plans, often offering quantified predictions with no acknowledgment of potential error. See, e.g., Press Release, The White House, American Recovery and Reinvestment Act: State-by-State Jobs Impact (Feb. 13, 2009). These were highly uncertain predictions, of course, and the White House knew it, but the false precision reflected political demands for an appearance of confidence. 
importance of the issue and the frequency of its discussion therefore should not be surprising. ${ }^{26}$ But this gap has been exceedingly large.

Scholarly attention also has been limited. Environmental law scholars often debate the proper balance of protection levels and compliance costs, and the methodologies through which those balances should be set. ${ }^{27}$ Environmental law scholars also have spent years exploring why actual outcomes so often fall short of legislative mandates. ${ }^{28}$ Finally, particularly in the past two decades, many academics have examined the legal implications of environmental instability and uncertainty. ${ }^{29}$ Problems of planning uncertainty lie at the intersection of all of these inquiries. But only a few studies address the approaches of particular statutes or agencies to uncertainties about plan success. ${ }^{30}$ While the extensive precautionary principle literature confronts related subjects, it provides little useful guidance on questions of planning uncertainty. ${ }^{31}$ The adaptive management

26. See Wagner, supra note 19, at 221-57 (explaining why Congress ignores the limitations of scientific knowledge).

27. Much of the voluminous debate about cost-benefit analysis, for example, addresses methodologies for determining outcome standards. See generally Thomas O. McGarity, Professor Sunstein's Fuzzy Math, 90 GEO. L.J. 2341 (2002) (discussing the process of creating drinking water standards for arsenic and critiquing Professor Sunstein's methodologies); Cass R. Sunstein, The Arithmetic of Arsenic, 90 GEO. L.J. 2255 (2002) (discussing the process of creating drinking water standards for arsenic).

28. See, e.g., Daniel A. Farber, Taking Slippage Seriously: Noncompliance and Creative Compliance in Environmental Law, 23 HARv. ENVTL. L. Rev. 297, 301-03, 320-22 (1999).

29. See, e.g., Daniel A. Farber, Eco-Pragmatism: Making Sensible ENVIRONMENTAL DECISIONS IN AN UNCERTAIN WORLD 35-36 (1999); Mary Jane Angelo, Harnessing the Power of Science in Environmental Law: Why We Should Why We Don't, and How We Can, 86 Tex. L. REv. 1527, 1531 (2008) ("One of the biggest challenges of the legal system is to be able to address the uncertainty inherent in science."); A. Dan Tarlock, The Nonequilibrium Paradigm in Ecology and the Partial Unraveling of Environmental Law, 27 LoY. L.A. L. REV. 1121, 1122-23 (1994). See generally Jonathan Baert Wiener, Law and the New Ecology: Evolution, Categories, and Consequences, 22 EcoloGY L.Q. 325 (1995). These sources represent the tip of an iceberg, and the nonlegal literature addressing environmental uncertainty is even more extensive.

30. See, e.g., Josh Eagle \& Barton H. Thompson, Jr., Answering Lord Perry's Question: Dissecting Regulatory Overfishing, 46 OCEAN \& COASTAL MGMT. 649, 653-76, (2003); James D. Fine \& Dave Owen, Technocracy and Democracy: Conflicts Between Models and Participation in Environmental Law and Planning, 56 HASTINGS L.J. 901, 933-34 (2005) (discussing the Clean Air Act's approach to planning uncertainty); Thomas $O$. McGarity, Judicial Enforcement of NEPA-Inspired Promises, 20 ENVTL. L. 569 (1990) (exploring judicial tolerance for mitigation measures with uncertain prospects of success); Kevin Cassidy, Comment, Endangered Species'Slippery Slope Back to the States: Existing Regulatory Mechanisms and Ongoing Conservation Efforts Under the Endangered Species Act, 32 ENVTL. L. 175 (2002) (discussing reliance on state conservation plans).

31. A strong precautionary principle might resolve this dilemma by requiring plans to either create certainty of success or ban environmentally threatening activities. See Sunstein, 
literature necessarily confronts issues of planning failure, as that literature begins with the observation that our predictive capacities are limited and that failures therefore are inevitable. ${ }^{32}$ But legal-academic proponents of adaptive management typically prescribe monitoring and adjustment systems designed to change course as problems emerge, and say little-or are overtly skeptical-about attempted reforms designed to improve ex ante decisionmaking. ${ }^{33}$ This Article therefore addresses a question that, while basic, remains largely unexplored: what assurance of success should environmental plans provide?

In Part II, I begin that analysis by exploring existing legislative and administrative approaches to planning uncertainty within some of the most important areas of environmental regulation. That analysis demonstrates the pervasiveness of these issues; across multiple areas of environmental policy, uncertainties about plan effectiveness recur, usually with significant consequences. While approaches vary, several themes emerge. As discussed above, neither legislation nor generalized rulemaking processes have done much to address these uncertainties. In the absence of such systematic attention from lawmakers, agency staff members often address questions of plan uncertainty on an ad hoc basis, sometimes with little transparency. When agencies do directly confront these issues, or when the courts intervene, the common consequence still is a preference for plans thought to have only slightly better than even odds of success. Problems of planning uncertainty have not been entirely ignored. In most contexts, some combination of statutes, regulatory guidance, and judicial decisions has provided at least a little legal direction, and I found no clear evidence that agencies are now systematically and intentionally approving plans as risky as the summer flounder quota at

Precautionary Principle, supra note 13, at 1011-16 (describing versions of the principle). That approach would not work in many contexts, however, because of trade-offs among competing environmental goals or because a total prohibition is not appropriate or politically acceptable. See id. at 1004. A more moderate precautionary principle, which holds that in conditions of uncertainty we should err in the direction that avoids irreversible environmental damage, is more workable and provides a basis for agencies to do more than just adopt the least stringent plan that might succeed, but otherwise provides only very general guidance about how much certainty plans should provide.

32. See generally Holling ET AL., supra note 12; KaI N. LeE, COMPASS AND GYrosCoPe: INTEGRATING SCIENCE AND POLITICS FOR THE ENVIRONMENT (1993).

33. See discussion infra Part III.C (discussing adaptive management literature). 
issue in Daley. ${ }^{34}$ But the patchwork of present approaches has not produced a transparent system, or a system more than mildly averse to risks of plan failure.

In Part III, I explain why these conclusions are cause for concern. Resolving this issue on an ad hoc, nontransparent basis impedes participation and accountability, both of which our governance system appropriately values. ${ }^{35}$ That approach also undermines evaluations of agency performance; without probability standards, it can be difficult to discern whether plan failures result from appropriate policy choices or flawed decisionmaking approaches. Ad hoc resolution of uncertainty questions also likely exacerbates the effects of heuristic biases, free riding, and other sorts of agency behaviors likely to increase gaps between congressionally mandated environmental goals and actual outcomes. ${ }^{36}$ Similarly, even a moderately high tolerance for risk assures that many plans will fail, leading not only to slippage but also to the frequent and costly need to adapt existing plans or to develop new ones. ${ }^{37}$ Whether one supports the full achievement of environmental statutes' goals or considers those goals to be excessively ambitious, the expense, contentiousness, and regulatory uncertainty created by repeated plan revisions are all good reasons to want plans with a high likelihood of fulfilling statutory mandates. And where correcting a failed plan is not possible, failure can lead to irreversible and ostensibly illegal environmental harm.

I therefore propose both procedural and substantive reforms. To improve procedure, lawmakers should create specific and generally applicable standards for the probability of plan success. In theory, those standards could come from Congress, though it probably is unrealistic to expect legislators to candidly acknowledge the reality that their prescribed planning approaches will not always work out. More realistically, agencies should build on congressional signals, or fill the voids where they are absent, by promulgating rules for managing uncertainties about the effectiveness of plans. On substance, those rules should both require uncertainty discussions and set maximum levels of tolerable failure risk, ${ }^{38}$ and thus should move

34. This Article does not demonstrate that such systematically permissive approaches are not occurring. I simply did not find strong, current, and uncontroverted evidence in the areas I reviewed.

35. See discussion infra Part III.A.

36. See discussion infra Part III.A.

37. See discussion infra Part III.B.

38. In most circumstances, meaningful standards are likely to be qualitative, for the kind of quantitative precision described in Daley is rarely possible. Qualitative uncertainty 
agencies away from the presently common practice of ad hoc and opaque plan uncertainty management. Those standards should not demand exact quantification of failure odds; because of the uncertainties surrounding environmental predictions, precise quantification of success probabilities is often impossible. ${ }^{39}$ Those standards usually also should not strive to eliminate all plan failure, for in an uncertain world, that goal also is often unrealistic. ${ }^{40}$ But the standards should demand at least qualitative estimates of the likelihood of failure, and they should attempt to reduce the frequency with which failures occur.

These reforms are likely to create incremental improvements rather than wholesale change. They would not eliminate the importance of a long-running debate about whether planning-based approaches should enjoy such prominence in environmental law, or whether they should be more extensively displaced by technologybased regulation or some alternative system. ${ }^{4 l}$ When agencies respond to probability standards, as they sometimes will, by producing more optimistic predictions rather than by adopting more cautious plans, the standards will produce slight change, at most. ${ }^{42}$ Similarly, where data are thin and environmental systems poorly understood, probabilities are likely to be uncertain, and assertions of compliance with probability standards will be educated estimates. Consequently, while these reforms should reduce decisional error, they will not eliminate it,

standards can still guide decisionmakers, however, as legal standards like "beyond a reasonable doubt" demonstrate.

39. Agencies often do produce quantitative predictions and quantitative error analyses, and if decisionmakers understand that those numbers are not precise and accurate predictions, there is nothing wrong with using those predictions to inform regulatory choices.

40. The exception, of course, occurs if plan failure would have catastrophic or serious and irreversible effects. Then, certainty, or something very close to it, is a reasonable goal.

41. The promoters of planning-based approaches typically cite their potential to tailor regulatory intensity to desired outcomes, avoiding overregulation or underregulation. See, e.g., Bruce A. Ackerman \& Richard B. Stewart, Reforming Environmental Law, 37 STAN. L. REV. 1333, 1334-40 (1985); William F. Pedersen, Jr., Turning the Tide on Water Quality, 15 ECOLOGY L.Q. 69, 87-89 (1988). Skeptics argue that challenges of creating individualized regulatory regimes for each planning area are enormous, and contend that the primary alternative, technology-based standards, is much more feasible, though by no means perfect. See, e.g., Oliver A. Houck, Of Bats, Birds and B-A-T: The Convergent Evolution of Environmental Law, 63 Miss. L.J. 403, 410-28 (1994); Wendy E. Wagner, The Triumph of Technology-Based Standards, 2000 U. ILL. L. REv. 83.

42. This already happens sometimes, and would likely happen more if probability standards create an incentive to produce optimistic predictions. See, e.g., Fine \& Owen, supra note 30 , at 956-57. But the professional norms of agency scientists are likely to create some resistance to such changes, particularly where the new assumptions seem less credible. 
and other corrective measures will remain essential. ${ }^{43}$ But these reforms would contribute to more coherent environmental planning processes, in which somewhat more deliberative dialogues address the possibility of plan failure, and in which gaps between desired and actual environmental outcomes are somewhat smaller. In a field in which dramatic reform has proven elusive, such incremental improvements are well worth pursuing.

\section{EXISTING APPROACHES}

If the dilemma presented in Daley was unique to fisheries management, it would be an obscure sideshow to the main body of environmental law. But that dilemma recurs, often barely noticed, throughout environmental law. This Part provides a detailed exploration of some of the key contexts in which planning uncertainties arise. I begin with fisheries regulation, which has presented these questions particularly starkly. I then focus on several of the most consequential areas of environmental policy - air quality, biodiversity protection, environmental impact assessment, and water quality. I also consider nuclear waste policy, which, while arguably less important, presents an interesting example of a different approach. I close by considering climate change, which is likely to present a new set of planning uncertainty challenges. The discussion is not comprehensive; these questions emerge in too many contexts for one article to address all. ${ }^{44}$ But the survey illustrates the range of typical approaches and amply demonstrates that the issue is very important.

The survey is also striking in what it does not find. While few categorical statements are possible, there is a paucity of strict, generally applicable standards enacted through legislation or rulemaking. Some statutes provide very general direction, but Congress has never enacted a law with clear and risk-averse guidance on probability standards, which standards the implementing agency then fleshed out through consistent, generally applicable regulations. In other words, environmental law never has addressed these questions the way our administrative law system is often assumed to approach

43. In Part III.C, I consider the relationship between the reforms I propose and theories of adaptive management. Despite possible superficial appearances of contradiction, I see the approaches as compatible.

44. See, e.g., 30 U.S.C. $\S 1235$ (2006) (setting forth requirements for abandoned mine reclamation plans); Vineyard Area Citizens for Responsible Growth v. City of Rancho Cordova, 150 P.3d 709 (Cal. 2007) (evaluating water supply planning). 
important issues. ${ }^{45}$ Nor is there much evidence that an alternative "new governance" model, in which local governments and stakeholders debate these issues and arrive at solutions tailored to local circumstances, has emerged or is likely to do so. Congressional direction, to the extent it exists, usually provides little constraint. Agencies have adopted ad hoc approaches, often with little debate, or, in rare cases, have followed rules imposed by the courts. ${ }^{46}$ That does not mean the issue has been ignored; in most areas, some combination of vague statutory directives, judicial decisions, and agency policy guidance has created at least some direction, and some of the resulting constraints appear to have affected outcomes. ${ }^{47}$ Moreover, even where legal guidance is minimal, the professional culture of agency staff sometimes dampens willingness to adopt plans with extremely low success odds. ${ }^{48}$ But problems of opacity and tolerance for plans with moderately low success odds often remain.

\section{A. Fisheries}

The Magnuson-Stevens Fishery Conservation and Management Act (Magnuson-Stevens Act) ${ }^{49}$ is the nation's primary regulatory statute for saltwater and anadromous fisheries. It seeks to limit foreign fishing boats' access to American waters, to provide economic protection and stability to fishermen and their communities, and to prevent overfishing. ${ }^{50}$ Overfishing, according to the MagnusonStevens Act, exceeds the "optimum yield" at which the fishery will be both sustainable and maximally productive. ${ }^{51}$

To implement its anti-overfishing mandate, the MagnusonStevens Act relies on a planning-based system. Using research produced by NOAA Fisheries ${ }^{52}$ and an ample dose of discretionary judgment, regional fishery management councils develop fishery

45. See DANiel A. Farber et al., CaSes and Materials on ENVIRONMENTAl LaW 360-61 (7th ed. 2006).

46. For advocacy of this model, see Michael C. Dorf \& Charles F. Sabel, $A$ Constitution of Democratic Experimentalism, 98 COLUM. L. REv. 267, 286-88 (1998).

47. See, e.g., infra notes 72-74, 175-190 and accompanying text.

48. See discussion infra Part II.B (describing interviews with EPA air quality staff).

49. 16 U.S.C. $\S \S 1801-1891$ c (2006).

50. Id.

51. Id. $\S 1851(\mathrm{a})(1)$.

52. See Eagle \& Thompson, supra note 30 , at 655 (describing research by NOAA's Fisheries Science Centers). 
management plans and annual fishing quotas..$^{53}$ They also allocate those quotas among groups of fishers and select regulatory measures designed to ensure that the quotas are not exceeded. ${ }^{54}$ The councils submit their plans and quotas to NOAA Fisheries, and as long as the plans and quotas are consistent with the Magnuson-Stevens Act, NOAA Fisheries must approve them. ${ }^{55}$ Unlike many pollution control statutes, which rely on overlapping planning and technology-based controls, no complementary set of feasibility-driven standards provides backup, and fishery management depends primarily upon this planning-based approach. ${ }^{56}$

Throughout their planning, the management councils and NOAA Fisheries must contend with uncertainties. Even without human influence, many fish populations would vary stochastically, leaving year-to-year populations unpredictable and potentially obscuring longterm trends. ${ }^{57}$ Available data are often scant or of suspect quality, compromising the validity of estimates of species' status. ${ }^{\text {s8 }}$ Animosities between agency scientists and fishers exacerbate uncertainties by impeding information flow. ${ }^{59}$ The effectiveness of regulatory measures is often unpredictable. Fishers have significant incentives to maximize their catch, and they often catch more than

53. The plan itself may set the quota, or the quotas may be set through annual decisions. In Daley, the latter approach was at issue. NRDC v. Daley, 209 F.3d 747, 750 (D.C. Cir. 2000).

54. See 16 U.S.C. $\S \S 1852(\mathrm{~h}), 1853$.

55. See Josh Eagle et al., TAKING Stock of THE Regional Fishery Management COUNCILS 1, 11 (2004) ("NMFS generally has not attempted to override the decisions of the councils."); Scott C. Matulich et al., Policy Formulation Versus Policy Implementation Under the Magnuson-Stevens Fishery Conservation and Management Act: Insight from the North Pacific Crab Rationalization, 34 B.C. ENVTL. AFF. L. REV. 239, 241 (2007) ("NMFS has no authority to revise a council-submitted FMP, amendment, or proposed regulation to suit its own policy preferences ....").

56. See, e.g., Pronsolino v. Nastri, 291 F.3d 1123, 1126-27 (9th Cir. 2002) (describing the Clean Water Act's reliance on complementary technology-based and planning-based regulatory approaches).

57. See OCEan Studies Bd., Div. On Earth \& Life Studies, Nat'l Research Council, Science and Its Role IN THe National Marine Fisheries Service 16 (2002) (describing uncertainties).

58. See EAGLE ET AL., supra note 55, at 16-19; Eagle \& Thompson, supra note 30, at $653-76$.

59. Scientists depend upon fishers for data, but fishers are sometimes reluctant to provide information, and agency scientists are often reluctant to credit the anecdotal and unquantified information fishers can provide. See Ilene M. Kaplan \& Bonnie J. McCay, Cooperative Research, Co-Management and the Social Dimension of Fisheries Science and Management, 28 MARINE POL'Y 257, 257-58 (2004) (noting "adversarial relations and tensions ... between the government sector and fishing community"); Alec Wilkinson, The Lobsterman, NEW YORKER, July 31, 2006, at 58-59. 
regulators ostensibly intended to allow. ${ }^{60}$ Agency staff reviewing proposed fishery management plans or quotas therefore can hardly ever provide absolute assurance that a plan will work. ${ }^{61}$

Despite those pervasive uncertainties, the Magnuson-Stevens Act provides limited guidance on the level of assurance that planning decisions must provide. The Magnuson-Stevens Act clearly states that ending overfishing is an overall statutory mandate. ${ }^{62}$ But the Act provides no prescription for the requisite level of certainty for each plan. $^{63}$ While NOAA Fisheries' regulations sometimes require that plans "assure" achievement of the statutory goal, ${ }^{64}$ "assure" is not a precise term, and the agency has never promulgated any sort of generalized regulation or even nonbinding guidance defining a more precise meaning. As the United States Court of Appeals for the Fourth Circuit explained in Fishermen's Dock Cooperative, Inc. v. Brown, ${ }^{65}$ the regulations simply "do not say what probability of success ... constitutes 'assurance' of success." ${ }^{.06}$ In the absence of such guidance,

60. See EAGLE ET AL., supra note 55, at 15 (describing causes of "overages").

61. Id. at 14. The authors explain:

NOAA scientists ... almost always present the councils with a range of possible MSYs. For example, scientists might tell a council that there is an 80 percent chance that the MSY is between 10 and 25 million pounds annually. This spread provides a council with a large amount of discretion. The council may choose to "set" the MSY of the fishery at any level between 10 million and 25 million pounds.

Id.

62. 16 U.S.C. $\S 1801(a)(6)$ (2006); NRDC v. Daley, 209 F.3d 747, 749 (D.C. Cir. 2000) (describing the Act's structure).

63. Even since 2007, when Congress tightened deadlines for ending overfishing and required catch limits within the range recommended by scientific and technical advisory bodies, the Act has imposed only a minimal limitation. See 16 U.S.C. § 1852(h)(6). Those limitations should preclude decisions by the FMCs to set catch levels higher than the highest level suggested by fisheries' scientists, but they will not independently prevent decisions to set the limit within, but near, the upper end of the range. See Eagle \& Thompson, supra note 30, at 660 (describing "strong" and "weak decision overfishing"). One might argue that deadlines indicate the need for a fairly high level of certainty. The Clean Air Act, however, contains similar deadlines, and the EPA still often approves plans thought to have near even failure odds. See discussion infra Part II.B.

64. E.g., Daley, 209 F.3d at 750.

65. 75 F.3d 164, 172 (4th Cir. 1996). In Fisherman's Dock Cooperative, a fishing group argued that the plan provided too much assurance of success in preventing overfishing, rather than, as in Daley, too little. The Fourth Circuit rejected that argument. See id;; see also Holly Doremus, Science Plays Defense: Natural Resource Management in the Bush Administration, 32 ECOLOGY L.Q. 249, 299-301 (2005) (discussing Fishermen's Dock Cooperative).

66. Fishermen's Dock Coop., 75 F.3d at 172; see Daley, 209 F.3d at 752 ("[T]he trial court found that the Fishery Act expressed no clear intent as to the particular level of certainty a TAL must guarantee.....'). 
"the choice of how much assurance to indulge in must be a policy choice left to the reasonable exercise of the discretion of the statutorily authorized decision-makers," and those decisionmakers traditionally made their choices on an ad hoc basis. ${ }^{67}$

That ad hoc approach has done little to promote sustainable fishery management. The risky choice at issue in Daley was not atypical: according to Eagle et al., "rather than choosing a quota in the middle of the recommended range, the councils almost always chose quotas that were at or near the top of the range, making effective management unlikely."68 NOAA Fisheries generally acquiesces to those choices; the same authors found that, "during the study period ... [NOAA Fisheries] disapproved at best 0.4 percent of the individual management measures submitted by the councils." ${ }^{.69}$ The results were predictable and have been widely lamented: despite decades of regulation, overfishing remains pervasive. ${ }^{70}$ The consequences of that overfishing have sometimes been devastating."

Nevertheless, after Daley, fishery managers no longer have quite as much flexibility to select approaches acknowledged to have low odds of preventing overfishing. "Only in Superman Comics' Bizarro world," the United States Court of Appeals for the District of Columbia held, "where reality is turned upside down, could the Service reasonably conclude that a measure that is at least four times as likely to fail as to succeed offers a 'fairly high level of confidence."'?2 The court also explained what it considered to be a minimum standard: "at the very least ... 'to assure' the achievement of the target [mortality rate], to 'prevent overfishing,' and to 'be consistent with' the fishery management plan, the [overall fishing quota] must have had at least a $50 \%$ chance of attaining [the target mortality rate]. ${ }^{373}$ NOAA Fisheries and lower courts have since treated that fifty percent mark as

67. Fishermen's Dock Coop., 75 F.3d at 172.

68. EAGLE ET AL., supra note 55, at 1, 15 ("[C]ouncils face significant pressure to increase the size of fishery quotas and thus the amount of fishing rights that can be apportioned."); see Eagle \& Thompson, supra note 30, at 656-63 (describing management of the Gulf Coast king mackerel fishery).

69. EAGLE ET Al., supra note 55, at 32.

70. Id. at 4 .

71. See, e.g., Oliver A. Houck, On the Law of Biodiversity and Ecosystem Management, 81 MINN. L. REV. 869, 946-47 (1997) (describing the crash in Atlantic cod populations and the enormous resulting losses in jobs and income).

72. NRDC v. Daley, 209 F.3d 747, 754 (D.C. Cir. 2000). The "fairly high level of confidence" language came from an agency courtroom concession. Id. (internal quotations omitted).

73. Id. 
necessary, and sufficient, for a plan to meet the statutory goals. ${ }^{74}$ Daley thus did raise the bar, albeit not particularly high.

This story contains several notable features, many of which turn out to be typical. First, responses to planning uncertainty are crucial to the effectiveness of the regulatory program. Second, Congress provided only general guidance about how much assurance of success fishery management plans should provide. Nor did NOAA Fisheries ever fill the void by promulgating general rules. Nothing in agency rules explicitly stated that an eighteen percent chance of success was not good enough, and in practice, the agency routinely acquiesced to such low odds of success. Creating a generally applicable standard therefore fell to the courts. The resulting standard does appear to have triggered a slight shift toward less risky plans, removed some risky proposals from the scope of debate, and provided conservation groups a litigation hook to challenge plans that arguably are unlikely to succeed. ${ }^{75}$ It suggests, in short, that a probability standard can change outcomes. But the improvement is a halting one. If the Daley standard is consistently applied, almost half of the nation's fishery management plans still could turn out to be failures. ${ }^{76}$ The many adverse consequences of plan failure, including unsustainable

74. See, e.g., Coastal Conservation Ass'n v. Gutierrez, 512 F. Supp. 2d 896, 900 (S.D. Tex. 2007) (rejecting a plan that would not meet the fifty percent threshold); Oceana, Inc. v. Evans, No. Civ.A.04-0811 (ESH), 2005 WL 555416, at *16 (D.D.C. Mar. 9, 2005) (treating fifty percent as the threshold); Nat'l Audubon Soc'y v. Evans, No.Civ.A.99-1707 (RWR), 2003 WL 23147552, at *3, 5 (D.D.C. July 3, 2003); Fisheries of the Northeastern United States; Atlantic Bluefish Fisheries; 2006 Atlantic Bluefish Specifications; Quota Adjustment; 2006 Research Set-Aside Project, 71 Fed. Reg. 9471, 9474 (Feb. 24, 2006) (codified as amended at 50 C.F.R. pt. 648) (eliminating an alternative because it would not reach the fifty percent threshold) (treating fifty percent as the threshold); see also N.C. Fisheries Ass'n v. Evans, 152 F. Supp. 2d 870, 872 (E.D. Va. 2001) (allowing quota adjustments to be made to ensure the fifty percent threshold is met); Recreational Fishing Alliance v. Evans, $172 \mathrm{~F}$. Supp. 2d 35, 44-45 (D.D.C. 2001) (treating fifty percent as the threshold).

75. See sources cited supra note 74. The other possibility is that the standard has encouraged NOAA scientists to select models and assumptions that will make more optimistic predictions, ultimately producing no change in results. E-mail from Josh Eagle to author (Feb. 26, 2009) (on file with author). That is a difficult hypothesis to verify or falsify. But it seems plausible, based on the actions of agency staff in other contexts, to expect that scientists will sometimes, but not always, make those shifts, meaning that the probability standard will sometimes, but not always, change outcomes. See discussion infra Part II.C (describing Endangered Species Act implementation).

76. Josh Eagle, Regional Ocean Governance: The Perils of Multiple-Use Management and the Promise of Agency Diversity, 16 DuKE ENVTL. L. \& PoL'y F. 143, 159 (2006) (noting that the standard "still left the success of U.S. fisheries management to a slightly weighted coin toss"). 
overfishing, regulatory conflict, and potentially catastrophic economic risk to fishing communities, all likely would remain common. ${ }^{77}$

\section{B. Air Quality}

While systematic efforts to address plan uncertainty have been weak in fishery management, they have been even rarer and less visible for air quality planning. That is not because the issue is unimportant. Because Clean Air Act (CAA) implementation produces enormous costs and benefits, because the CAA places central importance on planning, and because air quality managers confront substantial uncertainties, the stakes are high. ${ }^{78}$ But neither Congress nor the Environmental Protection Agency (EPA) has provided a legal framework for deciding what success odds a plan should create, and in the absence of such a framework, agency discussions of uncertainty management are often minimal, opaque, and functionally nonreviewable. Agency modelers and planners do address these questions - rigorously and carefully, in their view-and some EPA offices are confident that their approaches are effective. ${ }^{79}$ The statutory and regulatory structure also contains measures to compensate for plan failures. ${ }^{80}$ But key decisions about plan uncertainty nevertheless have tended to occur with little transparency or public oversight, often with poor results. ${ }^{81}$

The CAA relies heavily on a planning-based approach. It requires the EPA to develop numeric standards, known as "national ambient air quality standards" (NAAQS), for air pollutants that "may reasonably be anticipated to endanger public health or welfare."

77. For a discussion of those consequences, see EAGLE ET AL., supra note 55, at 19, describing a complete closure of the Pacific rockfish fishery, and Houck, supra note 71 , at $946-47$.

78. See EPA, The Benefits and Costs of the Clean AIR ACt 1990 to 2010 iii (1999).

79. I base this assertion on interviews with staff members in the EPA's regional offices.

80. See 42 U.S.C. $\S 7502$ (c)(9) (2006) (outlining contingency measures). The EPA also requires new plans if existing plans fail to produce attainment.

81. See Fine \& Owen, supra note 30, at 938-70 (chronicling the failure of one SIP); Howard Latin, Regulatory Failure, Administrative Incentives, and the New Clean Air Act, 21 ENVTL. L. 1647, 1683-84, 1688 (1991) (identifying SIP deficiencies in air pollution regulation); Arnold W. Reitze, Jr., Air Quality Protection Using State Implementation PlansThirty-Seven Years of Increasing Complexity, 15 VILL. ENVTL. L.J. 209, $357-58$ (2004) (dismissing the SIP program as a "failure," largely because many areas remain in nonattainment).

82. 42 U.S.C. $\S \S 7408,7409$. Those standards are to "allow[] an adequate margin of safety." Id. $\S 7409$ (b)(1). According to the EPA, "In selecting primary standards that provide 
States with areas not in compliance with the NAAQS must develop "state implementation plans" (SIP) specifying the regulatory control measures the state will use to "attain" compliance. ${ }^{83}$ Each SIP or SIP revision must be submitted to the EPA for approval, along with a computer-model-based demonstration that the plan will produce attainment. ${ }^{84}$ The EPA must approve or reject each submission. ${ }^{85}$ If approved, SIPs create legal obligations, enforceable by state or federal regulatory authorities or by private parties. ${ }^{86}$ They also constrain future activities and planning. Transportation development must be consistent with a lawful SIP, and before approving any project in a nonattainment area, federal agencies and "metropolitan planning organization(s)" must demonstrate that the project will "conform" to the SIP and will not create or contribute to nonattainment. ${ }^{87}$ SIPs are not the CAA's exclusive mechanism for improving air quality; fuel standards, technology-based standards, and a variety of other controls all should complement planning. ${ }^{88}$ But planning theoretically should serve as a backstop and a unifying approach.

As with fishery management, air quality management is filled with uncertainties, and agencies are often unsure whether their plans will succeed. ${ }^{89}$ Some air pollutants-particularly ozone, which causes some of the most pervasive pollution problems - derive from complex chemical reactions, and pollutant levels do not respond linearly to

an adequate margin of safety, the Administrator is seeking not only to prevent pollution levels that have been demonstrated to be harmful but also to prevent lower pollutant levels that may pose an unacceptable risk of harm." National Ambient Air Quality Standards for Ozone, 73 Fed. Reg. 16,436, 16,437 (Mar. 27, 2008) (codified as amended at 40 C.F.R. pt. 56-58). The margin of safety in the NAAQS thus serves to ensure that air quality is better than currently thought necessary, not to accommodate planning error.

83. 42 U.S.C. $\S 7410$. The Act also requires states to plan for maintaining air quality in areas in compliance with the NAAQS. See id. $\S \S 7471,7473$.

84. E.g., id. $\S 7511(\mathrm{c})(2)(\mathrm{A})$

85. If a state does not submit a plan, or submits an inadequate plan, the EPA must prepare a substitute "Federal Implementation Plan." Id. \& 7410(c). The EPA generally strives to avoid this step. See Thomas O. McGarity, Missing Milestones: A Critical Look at the Clean Air Act's VOC Emissions Reduction Program in Nonattainment Areas, 18 VA. ENVTL. L.J. 41, 49 (1999) (describing the "vanishingly small" odds of FIP preparation).

86. 42 U.S.C. $\S 7413$.

87. Id. § 7506(c); see Envtl. Def., Inc. v. EPA, 509 F.3d 553, 555-57 (D.C. Cir. 2007) (describing the relationships between SIPs and conformity).

88. See Houck, supra note 41, at 418-22 (describing the CAA's increasing emphasis on complementary approaches).

89. See EPA, GUidance on tHE USE of Models and Other ANALYSES for DEMONSTRATING ATtAINMENT OF AIR QUALITY GOALS FOR OZONE, PM2.5, AND REGIONAL HAZE 12 (2007) ("There is uncertainty accompanying model predictions."). 
changes in source emissions. ${ }^{90}$ Shifting weather also introduces variability; wind and heat both affect locations and concentrations of air pollutants, and neither is entirely predictable. ${ }^{91}$ Economic fluctuations may affect energy consumption and thus fossil fuel combustion, unforeseen market trends or development patterns may change automotive or industrial emissions, and the enforceability of emissions control rules is often unpredictable. ${ }^{92}$ That does not mean planning is pure guesswork. State and federal air agencies have spent years improving their predictive techniques, and EPA employees are confident in some of their models' predictions. ${ }^{93}$ But attainment demonstrations still often contain layers of uncertainties.

Words sprinkled through the CAA provide general guidance about managing this uncertainty. For example, "[e]ach State shall have the primary responsibility for assuring air quality" throughout the state; SIPs "will specify the manner in which national primary and secondary ambient air quality standards will be achieved and maintained;"" and each SIP "shall provide for attainment of the national primary ambient air quality standards.", The CAA also requires specific enforceability and monitoring measures to help ensure that attainment actually occurs. ${ }^{96}$ Those statutory provisions suggest that the CAA probably would not allow the kind of risk tolerance that once was routine in fisheries planning."

Nevertheless, some ambiguity remains. Nowhere does the CAA expressly state a probability standard. Congress, if it understood the uncertainties inherent in air quality planning, probably would not demand certainty that a SIP would produce attainment, for such certainty might come only with extremely high compliance costs. Indeed, several sections of the CAA contemplate plan failure. For example, sections 7509 and 7511 specify consequences, including

90. New York v. EPA, 133 F.3d 987, 984-90 (7th Cir. 1998); McGarity, supra note 85, at 50 (describing "huge uncertainties" about ozone formation). EPA staff told me they were confident in their ability to model concentrations of directly emitted pollutants, but that ozone and particulate matter, which derive largely from precursor emissions, remain challenging.

91. See Fine \& Owen, supra note 30, at 914, 944-45 (describing mechanisms of ozone creation).

92. See id. at 960; Reitze, supra note 81 , at 361 .

93. E.g., Telephone Interview with Christos Panos, Envtl. Eng'r, EPA Region 5 (Sept. 30,2008 ) (describing some of EPA's models as "very, very accurate"); Telephone Interview with Marcia Spink, Assoc. Dir., Office of Air Programs, EPA Region 3 (Oct. 10, 2008) ("When we pop every grid cell green, that SIP works.").

94. 42 U.S.C. $\$ 7407$ (2000) (emphasis added).

95. Id. $\S 7502$ (c) (emphasis added).

96. Id. $\S \S 7410(\mathrm{a}), 7410(\mathrm{~m}), 7502(\mathrm{c})(6), 7509$.

97. See supra notes 68-70 and accompanying text. 
redesignation as a more severe classification of nonattainment area, if attainment deadlines are missed. ${ }^{98}$ Those provisions would seem unnecessary had Congress anticipated that initial attainment predictions would certainly be correct. ${ }^{99}$ The EPA therefore could reasonably argue that the CAA is not so clear as to eliminate the EPA's discretion to decide how much certainty is enough.

While Congress may have left this question unresolved, it cannot have escaped the attention of the EPA or of state air quality planners. Those state planners have developed, and the EPA has approved, dozens of SIPs and SIP amendments, and many agency staff members devote their careers to building and improving simulation models designed to manage uncertainties. ${ }^{100}$ Those state and federal planners have produced successes, ${ }^{101}$ but also have witnessed the demise of many plans; failures in areas like Los Angeles, Houston, or the San Joaquin Valley indicate that attainment demonstrations are sometimes highly uncertain. ${ }^{102}$ The EPA and the state planners also are well aware of the enormous effort that each SIP update requires, and know that while SIPs can be revised, plan failure is well worth avoiding ${ }^{103}$ The EPA therefore has sufficient experience and ample incentive to generate a consistent and cautious approach to uncertainty management.

Nevertheless, the EPA's attempts to create consistent approaches have been tentative and have encouraged plans with significant failure risk. The agency has never promulgated generally applicable regulations specifying what probability standard a SIP must satisfy. Its primary guidance document on approving SIPs does not even address

98. 42 U.S.C. $\$ \$ 7509,7511$.

99. In the 1990 Clean Air Act Amendments, Congress attempted to bolster the overall planning scheme by requiring states to submit plans for achieving incremental progress toward the overall goal. Compliance with that requirement has been poor, but its existence also suggests that Congress perceived a need for insurance against plan failure. See McGarity, supra note 85, at 89-90, 97.

100. Fine \& Owen, supra note 30, at 904 n.9; see, e.g., EPA, supra note 89 (prescribing approaches to uncertainty management).

101. Despite academic literature criticizing the SIP approach, see sources cited supra note 81 and accompanying text, the EPA employees I spoke with generally thought the approach worked reasonably well, and most cited specific success stories.

102. See McGarity, supra note 85, at 46-48. Commentators have argued that historic SIP approvals were premised on dubious rationales. See, e.g., David Schoenbrod, Goals Statutes or Rules Statutes: The Case of the Clean Air Act, 30 UCLA L. REv. 740, 771-74 (1983) ("EPA bent over backwards to approve whatever plans the states submitted.").

103. See EPA, supra note 89, at 4 ("Resource intensive approaches may often be needed to support an adequate attainment demonstration."); Fine \& Owen, supra note 30, at 950-58 (describing one amendment to a portion of California's ozone SIP). 
the question. ${ }^{104}$ The agency's only centralized effort to address the issue of plan uncertainty comes from a series of nonbinding modeling guidance documents, and those documents fall well short of clearly endorsing a risk-averse approach. ${ }^{105}$ Under the EPA's current guidance, a model that, with a weight-of-evidence adjustment, predicts design values $^{106}$ just barely below, or even equal to, ${ }^{107}$ the NAAQS still has demonstrated attainment. ${ }^{108}$ In other words, a model that predicts compliance only by a hair's breadth has shown attainment, and a SIP with no margin of error should be approved.

That recommendation is interesting on several levels. First, as nonbinding guidance, it allows alternative approaches, and the EPA's emphasis on utilizing weight-of-evidence techniques heightens the

104. State Implementation Plans; General Preamble for the Implementation of Title I of the Clean Air Act Amendments of 1990, 57 Fed. Reg. 13,498 (Apr. 16, 1992) (codified as amended at 40 C.F.R. pt. 52).

105. In its original guidance, the EPA encouraged its modelers to convey information about uncertainties and tentatively suggested reliance upon a best estimate. Requirements for Preparation, Adoption, and Submittal of Implementation Plans, 58 Fed. Reg. 38,816, 38,841 (July 20, 1993) (codified as amended at 40 C.F.R. pts. 51-52, 260, 266). The EPA asserted that "it is unclear how this information should be used to make an air pollution control decision," but then added that "it is easiest and tends to ensure consistency if the decisionmaker confines his judgment to use of the "best estimate' provided by the modeler." Id. A few paragraphs later, the EPA qualified that suggestion by stating that "[n]o specific guidance on the consideration of model uncertainty in decision-making is being given at this time." Id.

For years, and through multiple updates, that language remained unchanged. E.g., Revision to the Guideline on Air Quality Models: Adoption of a Preferred General Purpose (Flat and Complex Terrain) Dispersion Model and Other Revisions, 70 Fed. Reg. 68,218, 68,246-47 (Nov. 9, 2005) (codified as amended at 40 C.F.R. pt. 51); Requirements for Preparation, Adoption, and Submittal of Implementation Plans, 61 Fed. Reg. 41,838-41, 41,858-59 (Aug. 12, 1996) (codified as amended at 40 C.F.R. pts. 51-52). In 2007, the EPA issued additional guidance with new wording but a similar underlying approach. See generally EPA, supra note 89. The EPA again recommended reliance on the best estimate, supplemented by a weight-of-the-evidence check, but did not purport to bind its decisionmakers. See id. at 17-19.

106. The Clean Air Act allows three exceedances of the NAAQS over the course of a compliance period. 42 U.S.C. $\$ 7511$ (2006). For that reason, modelers focus on the fourthhighest value predicted by the model.

107. The EPA also rounds off its results, so it considers a prediction of a $0.084 \mathrm{ppm}$ concentration to constitute an attainment demonstration for a $0.080 \mathrm{ppm}$ standard. EPA, supra note 89 , at 40 .

108. Id at 40, 44; see also Telephone Interview with Lynorae Benjamin, EPA, Region 4 (Nov. 21, 2008); Telephone Interview with Doris Lo \& Sarvy Mahdavi, EPA Region 9 (Jan. 28, 2009); Telephone Interview with Carl Young and Carrie Paige, EPA Region 6 (Nov. 25, 2008). Mr. Young and Ms. Paige explained that their office tries to avoid overcontrolling because the associated compliance costs are serious, and Ms. Lo likewise explained that creating a significant margin of error would increase costs and generate resistance. I asked Ms. Benjamin how much margin of error the EPA typically demands; her answer was "not a lot." 
emphasis on flexibility and individualized judgment. ${ }^{109}$ EPA staff consistently told me that they eschew any formalized standard, and that while they take seriously the importance of assuring rigorous attainment demonstrations, they resolve questions of plan uncertainty on a case-by-case basis. ${ }^{10}$ Second, the guidance's recommended approach, if followed, would indulge a substantial risk of plan failure. In many contexts, scientists are unwilling to assert any conclusion with more than a five percent chance of being incorrect, ${ }^{111}$ yet here, where the likely consequences of error are air quality that violates legal requirements and the need for an expensive new planning effort, the EPA suggests a "best-estimate" approach likely to produce only slightly better than even odds of compliance. ${ }^{112}$

That approach also has important consequences for the transparency of SIP approvals. In the absence of any general standard for addressing the uncertain prospects of SIP success, decisions about uncertainty management can become not only ad hoc, but also invisible and unreviewable. The EPA approves SIPs through notice and comment rulemaking, but the rulemaking documents rarely discuss how confident planners are of their plans' prospects of success. ${ }^{113}$ Nor do many SIPs or attainment demonstrations contain such discussion. For example, in a recent study, James Fine and I found no discussion of confidence levels or margins for error, nor anything other than highly general and sometimes inaccurate

109. EPA, supra note 89, at 17-19.

110. Telephone Interview with Marcia Spink, supra note 93; Telephone Interview with Paul Truchan, EPA Region 2 (Sept. 29, 2008); Telephone Interview with Carl Young \& Carrie Paige, supra note 108.

111. Judith S. Weis, Scientific Uncertainty and Environmental Policy: Four Case Studies, in SCIENTIFIC UNCERTAINTY AND ENVIRONMENTAL Problem Solving 160 (John Lemons ed., 1996).

112. Some EPA staff told me that if a model predicted attainment prior to a weight-ofevidence determination, the plan would probably produce attainment, primarily because the models incorporate conservative assumptions. In other circumstances, however, air quality modelers have adopted key assumptions that were not at all conservative. See, e.g., Fine \& Owen, supra note 30, at 930 n.144, 962-65 (quoting a meteorologist who had been involved in multiple unsuccessful SIP amendments and describing a failed SIP amendment).

113. I base this assertion on Westlaw searches of SIP approval documents (which the EPA publishes in the Federal Register) from the years 1997 and 2007. I selected those years randomly, except that I deliberately chose years with different presidential administrations. With few exceptions, those approval documents say hardly anything about addressing plan uncertainty. However, EPA Region 6 staff pointed me to a recent proposed approval for the Dallas-Fort Worth Area. They thought, and I agree, that the proposed rule provides a clear and accessible discussion of uncertainty management. See, e.g., Approval and Promulgation of Air Quality Implementation Plans; Texas; Attainment Demonstration for the Dallas/Fort Worth 1997 8-Hour Ozone Nonattainment Area, 73 Fed. Reg. 40,203 (proposed July 14, 2008) (to be codified 40 C.F.R. pt. 52). 
discussion of uncertainties; yet we were reviewing a SIP that had faced long odds of success. ${ }^{114}$ That does not mean such uncertainties are not confronted. Inevitably they are; as modelers make assumptions and integrate data into their models, they decide how much error risk they are willing to accept. ${ }^{115}$ Sometimes they know they are adopting risky plans. In other circumstances, they may be quite confident that their plans are conservative, or that uncertainties are minimal. ${ }^{116}$ But to external observers, and even perhaps to nonmodelers within the agency, those decisions can be all but invisible.

That invisibility creates a significant distinction between uncertainty management in air quality planning and in fishery management. While in fishery management the presence of confidence estimates facilitates oversight, including judicial review, and ultimately allowed for the D.C. Circuit to establish a generally applicable standard for managing uncertainty, no parallel process has occurred in CAA litigation. Environmental Defense v. EPA, ${ }^{117}$ a recent case involving the EPA's approval of a New York State SIP, illustrates the difference. Rather than predicting compliance, New York's simulation model predicted nonattainment by a wide margin. ${ }^{118}$ When the EPA checked the modeling, it obtained similar results. ${ }^{119}$ Based on their judgment that the modeled prediction rested on uncertain assumptions and conservative methodologies, New York and the EPA both used a weight-of-evidence approach to revise their models' estimates to levels closer to, but still exceeding, the regulatory standard. ${ }^{120}$ They then relied on the state's promise to implement additional regulatory measures - a promise that the state did not

114. Fine \& Owen, supra note 30 , at $960-62$.

115. Modelers also employ multiple techniques to determine the extent of uncertainty. See, e.g., EPA, supra note 89, at 205-08 (providing examples of graphical representations of model performance).

116. See Fine \& Owen, supra note 30, at 957 n.286 (quoting a state regulator acknowledging that an approved SIP amendment had "long odds" of success); sources cited supra note 93 (describing confidence in some predictions).

117. 369 F.3d 193 (2d Cir. 2004).

118. Id. at 198 (the regulatory one-hour standard for ozone was 120 parts per billion, and New York's model runs predicted values of 169 and 171 parts per billion).

119. Id. at 199.

120. Id. at 198-200. Such corrections are common. Because models are imperfect tools, modelers are wary about letting model results trump observational data or common sense. See EPA, supra note 89, at 17-19 (explaining the reasons for using a "weight of evidence determination"). But there are dangers in such adjustments. One of the best uses of models is to test conventional wisdom, and if modelers use conventional wisdom to adjust modeling results, the modeling process risks circularity. Differentiating adjustments made because of informed professional judgment from those made because of political pressure or administrative convenience also can be difficult. 
keep-to support their ultimate prediction of attainment. ${ }^{121}$ With all that adjustment, the resulting attainment demonstration cannot have produced strong odds of success. ${ }^{122}$ But the EPA's approval decision says hardly anything, quantitative or qualitative, about those odds. ${ }^{123}$ The reviewing court did not even consider whether the plan's prospects of success were too uncertain, and Environmental Defense--an organization experienced with air quality litigation and one of the prevailing plaintiffs in Daley - focused on other issues. ${ }^{124}$ The requisite level of certainty was clearly an important policy issue-millions of people breathe New York City's air-and could have been an important legal issue. Instead, it disappeared from view.

\section{Endangered Species}

If air quality management exemplifies a highly discretionary approach to planning uncertainty, Endangered Species Act (ESA) implementation follows a slightly more legalized model. ${ }^{125}$ The ESA provides slightly more guidance than the CAA. The agencies primarily responsible for implementing the ESA have fleshed out that statutory language with guidance documents. The resulting prescriptions are a little vague, somewhat internally inconsistent, and leave room for substantial discretion. But on paper they are nevertheless more robust than the approach created by the EPA's CAA guidance. The agencies' checkered implementation record indicates that a paper standard does not automatically translate into revised outcomes; while the ESA and guidance ostensibly require caution, the implementing agencies have often indulged plans with poor odds of success. ${ }^{126}$ Nevertheless, those standards, although sometimes ignored

121. Envtl. Def., 369 F.3d at 200.

122. In an interview, I asked an EPA planner from Region 2 whether the agency would issue an approval if presented with a SIP that planners felt had about a sixty percent chance of succeeding. He responded that a sixty percent chance seemed too low. Telephone Interview with Paul Truchan, supra note 110. That suggests that the approval in Environmental Defense v. EPA may have been more risky than the norm, at least for Region 2. But, compared with outcomes in other major urban regions, the result seems hardly anomalous.

123. See generally Approval and Promulgation of Implementation Plans, 67 Fed. Reg. 5170 (Feb. 4, 2002) (codified as amended at 40 C.F.R. pt. 52). The document discusses potentially uncertain assumptions, and offers justifications for relying upon those assumptions, but contains no attempt to synthesize its uncertainty analysis into an overall assessment, quantitative or qualitative, of success odds.

124. See Envtl. Def., 369 F.3d at 200 (describing Environmental Defense's claims).

125. 16 U.S.C. $\S \S 1531-1544$ (2006).

126. See, e.g., Alejandro E. Camacho, Can Regulation Evolve? Lessons from a Study in Maladaptive Management, 55 UCLA L. REv. 293, 297 (2007) (describing a tendency toward "risky regulatory approvals"); infra notes 151-157 and accompanying text. 
or circumvented, do appear to have changed some outcomes. ${ }^{127}$ Thus, the ESA illustrates both the limitations and promise of even general guidance on plan uncertainty: while susceptible to circumvention and by no means a panacea, such guidance can change results.

In several ways, the ESA emphasizes prospective planning. When listing or delisting species, the wildlife agencies must consider whether existing regulatory measures will be adequate to protect the species, and those measures often derive from state or federal plans. ${ }^{128}$ Once species are listed, actions that "take" listed species are generally prohibited, but the ESA creates an exception for "takes" consistent with approved "habitat conservation plans." federal agencies from taking actions likely to jeopardize the continued existence of listed species, but federal agencies may proceed with "reasonable and prudent alternatives" to actions that might create jeopardy, and those reasonable and prudent alternatives usually involve some sort of mitigation plan or project modification designed to avoid jeopardy. ${ }^{130}$ Finally, when species are listed, the wildlife agencies may develop recovery plans specifying measures that should facilitate the species' eventual delisting. ${ }^{131}$ Consequently, many of the implementing agencies' decisions are contingent upon their predictions about the performance of some sort of plan.

Because of pervasive uncertainties, agencies rarely can guarantee that their plans will succeed. ${ }^{132}$ Information deficits are ubiquitous, for understanding species' needs often requires more research than agencies have budgets to perform, and academic research priorities do not often match agencies' information needs. ${ }^{133}$ Species populations tend to vary stochastically and to be sensitive to a range of influences,

127. See infra notes $158-164$ and accompanying text.

128. 16 U.S.C. $\S 1533(\mathrm{a})(1)(\mathrm{D})$.

129. Id. §§ 1538-1539; see Camacho, supra note 126, at 301-06.

130. 16 U.S.C. \& 1536; see, e.g., Oliver A. Houck, The Endangered Species Act and Its Implementation by the U.S. Departments of Interior and Commerce, 64 U. COLO. L. REV. 277, 317-22 (1993) (describing reasonable and prudent alternatives).

131. 16 U.S.C. $\S 1533(\mathrm{f})$.

132. See COMM. ON SCIENTIFIC ISSUES IN THE ENDANGered Species ACT, BD. ON ENVTL. STudies \& TOXICOLOGY, COMM'N ON LIFE SCIS., NAT'L RESEARCH COUNCIL, SCIENCE AND THE ENDANGERED SPECIES ACT 143-54 (1995); Fraser Shilling, Do Habitat Conservation Plans Protect Endangered Species?, 276 SCI. MAG. 1662, 1663 (1997) (noting that habitat conservation plans typically "lack adequate baseline information about population size of target species and actual habitat use, primarily because of the generalized lack of such information").

133. See Holly Doremus, Data Gaps in Natural Resource Management: Sniffing for Leaks Along the Information Pipeline, 83 IND. L.J. 407, 417-23 (2008). 
some of them also variable in their intensity. ${ }^{134}$ Endangered species protection also depends upon human behavior, with variations in development pressure and resource needs all affecting the availability of habitat and the ease or contentiousness of implementing regulatory constraints. Consequently, plans for species protection and recovery rarely come with guarantees attached. ${ }^{135}$

The ESA itself provides some general guidance about how such uncertainties should be addressed. The overarching purposes of the ESA suggest a strongly protective approach - as the United States Supreme Court famously stated, the "language, history, and structure of the [ESA] indicate[] beyond doubt that Congress intended endangered species to be afforded the highest of priorities"- but that approach is not prescribed in language sufficiently specific to foreclose some interpretive discretion. ${ }^{136}$ Species must be listed as endangered if they are in "danger" of extinction or as threatened if they are "likely" to face such danger "in the foreseeáble future."137 While those terms do not demand certainty about the species' safety, a species cannot be out of danger if its survival hinges on a plan with less than a coin toss's odds of providing sufficient protection. ${ }^{138}$ Similarly, federal agencies must ensure that their actions are "not likely to jeopardize the continued existence" of a listed species or adversely modify a critical habitat. ${ }^{139}$ While "jeopardize," which the ESA does not define, is an amorphous term, ${ }^{140}$ "likely" again implies a probability standard. It suggests that an action that might jeopardize a species, but probably will not, could legally proceed while an action

134. See Holling ET AL., supra note 12, at 33-35; NAT'L ReSEARCH COUNCIL, supra note 132 , at $144-45$.

135. See NAT'L RESEARCH COUNCIL, supra note 132, at 145 ("[C]ritical data ... are usually lacking.").

136. Tenn. Valley Auth. v. Hill, 437 U.S. 153, 174 (1978).

137. 16 U.S.C. $\$ 1532(6)$, (20) (2006) (defining "endangered" and "threatened" species); id. $\S 1533$ (describing the factors used in determining whether a species is "endangered" or "threatened").

138. See, e.g., W. Watersheds Project v. Fish \& Wildlife Serv., 535 F. Supp. 2d 1173, 1183-85 (D. Idaho 2007) (rejecting an application of this standard); Trout Unlimited v. Lohn, Civ.No.06-1493-ST, 2007 WL 2973568, at *13-18 (D. Or. July 13, 2007) (discussing the meaning of the "likely" standard).

139. 16 U.S.C. $\S 1536(a)(2)$.

140. See Daniel J. Rohlf, Jeopardy Under the Endangered Species Act: Playing a Game Protected Species Can't Win, 41 WASHBURN L.J. 114, 126-28 (2001) (explaining possible interpretations of the term). 
that might be harmless but probably will have a jeopardizing effect would be illegal. ${ }^{141}$

Habitat conservation plans (HCPs) involve a similar standard. An HCP may be approved, and species may be taken, only if the permittee provides assurances of adequate funding and if "the taking will not appreciably reduce the likelihood of the survival and recovery of the species in the wild." ${ }^{42}$ That language does not suggest that an HCP must create certainty that the species will survive; arguably, a species' overall survival and recovery odds will be improved as long as the conservation measures have better than even odds of offsetting the take. But that language does indicate that an HCP that might benefit the species, but more likely will lead to increased threats, should not be approved. Only with recovery plans does the ESA provide no guidance at all. While those plans are to facilitate species survival and "conservation," a term defined as improvement sufficient to allow delisting, the statute does not say how sure the agencies must be that the plans will achieve those goals. ${ }^{143}$

With most federal environmental statutes, there has been a dearth of generally applicable agency regulations, or even guidance documents with some measure of specificity, fleshing out the appropriate approach to plan uncertainty. ESA implementation is partly consistent with that trend; while the United States Fish \& Wildlife Service (FWS) and NOAA Fisheries have promulgated joint regulations, those regulations do little to flesh out the statutory language on probability standards. ${ }^{144}$ The agencies' implementation handbooks, however, do provide additional, and somewhat mixed, guidance on the management of plan uncertainty.

The agencies' consultation handbook explains that where outcomes are uncertain, "[t]he Services are then expected to provide

141. The analysis is complicated by language in the Endangered Species Act's legislative history stating that species should receive "the benefit of the doubt." H.R. REP. No. 96-697, at 12 (Conf. Rep.), reprinted in 1979 U.S.C.C.A.N. 2572, 2576; see Conner v. Burford, 848 F.2d 1441, 1454 (9th Cir. 1988) (citing this language as indicative of congressional intent).

142. 16 U.S.C. $\S 1539$ (a)(2)(B)(iv). Section 1539(a)(2)(B) also requires that the applicant provide "such other assurances as [FWS or NOAA Fisheries] may require that the plan will be implemented," but does not require FWS or NOAA Fisheries to actually demand such assurances. Id. at $\S 1539(\mathrm{a})(2)(\mathrm{B})$.

143. Id. $\S 1533(\mathrm{f})$ (lacking any reference as to how agencies shall ensure that their goals are met); id. § 1532(3) (defining "conservation").

144. See 50 C.F.R. $\S \S 402.02-402.16$ (2008) (consultation regulations). 
the benefit of the doubt to the species."145 Accordingly, the consultation handbook provides that where data gaps exist, the wildlife agency will either ask the action agency to fill those gaps or proceed while making cautious assumptions that favor the species. ${ }^{146}$ Though not particularly specific, that language clearly suggests that plan uncertainty should be managed with caution.

The HCP handbook suggests a more permissive approach, though the signals are mixed. While it cautions that "[t]he Services should not approve an HCP using conservation strategies that have a low likelihood of success," it also asserts that "the base mitigation strategy or initial minimization and mitigation measures ... must be sufficiently vigorous so that the Service may reasonably believe that they will be successful" and recommends adaptive management strategies, rather than outright permit denials, where significant uncertainties remain. ${ }^{147}$ Read in isolation, that "may reasonably believe" language would set the bar low, implying that even where outcomes are highly uncertain and reasonable people would disagree about the likely effectiveness of an HCP, it could be approved. But the HCP handbook also notes that an HCP approval is a federal action subject to section 7-including, presumably, the benefit-of-the-doubt requirements. ${ }^{148}$ It also requires that $\mathrm{HCPs}$ include funding guarantees sufficient to address unforeseen circumstances, and urges the inclusion of implementation commitments where the plan will depend upon third party actions. ${ }^{149}$ Finally, it exhorts, but does not require, the Services to ensure that HCPs provide net benefits for species. ${ }^{150}$

The records of FWS and NOAA Fisheries in implementing these provisions is mixed. $^{\text {Is }}$ In making listing decisions, the FWS and

145. NaT'L MARINe FiSheries SERV., U.S. FiSH \& WildLIFE SERV., ENDANGEREd Species act Consultation Handbook: Procedures for Conducting Section 7 CONSULTATIONS AND CONFERENCES 1-6 (1998).

146. See id. at 3-12 (stating that the services will not provide a "no effect" concurrence where there is uncertainty about possible effects, unless those effects are of insignificant magnitude or extremely low probability). Less conservatively, the Consultation Handbook also states that when the agencies are considering cumulative impacts, they should consider only other future actions that are "reasonably certain" to occur. Id. at 4-30.

147. NAT'L Marine Fisheries SERV., U.S. Fish \& Wildlife Serv., HabitaT Conservation Planning and Incidental Take Permit Processing Handbook 3-24 to 325 (1996) (emphasis added).

148. Id. at 7-4.

149. Id. at $7-4$ to $7-6$.

150. Id. at 3-21.

151. That record also is not well documented. While many case studies consider ESA implementation, the resulting evidence is largely anecdotal, and there are few data sets that allow consideration of the agencies' approach to plan uncertainty across a range of decisions. 
NOAA Fisheries have sometimes relied upon highly optimistic predictions of the success of existing management plans, even where those plans were quite inchoate. ${ }^{152}$ Observers have criticized this approach to consultation, arguing that instead of giving the benefit of the doubt to species, the FWS and NOAA Fisheries have systematically selected the least burdensome approach that might offer protection. ${ }^{153}$ Studies of the HCP process have produced similar conclusions, noting a tendency to adopt private developers' plans despite what appear to be marginal odds of success and minimal provisions for ongoing monitoring or adjustment. ${ }^{154}$ The agencies often seem to be interested primarily in ducking controversy as quietly as possible, ${ }^{155}$ and one easy way to do so is to use low probability standards and to adopt any plan that might work. ${ }^{156}$ That approach is, in theory, fundamentally inconsistent with the statutory directives and the handbooks' emphasis on providing species the benefit of the doubt. But with both ultimate outcomes and probabilities somewhat ambiguously defined by the statute, regulations, and guidance, the

Consequently, general conclusions about ESA implementation involve their own dose of uncertainty.

152. See, e.g., Houck, supra note 130, at 287-88 (describing reasons for not listing salmon runs and the northern spotted owl); Cassidy, supra note 30, at 177 (criticizing "a longstanding agency practice of deferring to state and local conservation efforts - even if those efforts are unimplemented, unproven, or voluntary-rather than listing a species under the ESA").

153. See Houck, supra note 130, at 316-21 (concluding that "there is little evidence that [formal consultation] is changing [outcomes] very much at all"); Rohlf, supra note 140, at 115 (" $[T]$ he concept of jeopardy often amounts to little more than a vague threat employed by FWS and NMFS to negotiate relatively minor modifications to federal and non-federal actions."); see also Holly Doremus, Scientific and Political Integrity in Environmental Policy, 86 TEX. L. REv. 1601, 1606-09, 1613-17 (2008) (documenting pressure to issue decisions less protective than agency scientists would have preferred, but also scientists' resistancesometimes successful, sometimes not- to that pressure). See generally Michael C. Blumm et al., Practiced at the Art of Deception: The Failure of Columbia Basin Salmon Recovery Under the Endangered Species Act, 36 ENVTL. L. 709 (2006).

154. See Camacho, supra note 126, at 323-35; Holly Doremus, Adaptive Management, the Endangered Species Act, and the Institutional Challenges of "New Age" Environmental Protection, 41 WASHBURN L.J. 50, 68-74 (2001); Shilling, supra note 132, at 1662-63 (describing one rather permissive plan).

155. See Doremus, supra note 154, at 58 ("[T] 1978 consists generally of the Services exploiting their discretion to the fullest to avoid political controversy.").

156. See Seattle Audubon Soc'y v. Evans, 771 F. Supp. 1081, 1089 (W.D. Wash.), aff'd, 952 F.2d 297 (9th Cir. 1991) (quoting agency staff describing pressure to take such permissive approaches). 
agencies can find sufficient flexibility to take such permissive approaches, or to shift approaches on a case-by-case basis. ${ }^{157}$

There are, however, contrasting indications that sometimes the implementing agencies act, or are judicially compelled to act, as though subject to probability standards with teeth. While the wildlife agencies have sometimes been rather optimistic in relying on protection plans to avoid listing, the courts have been more skeptical, generally rejecting reliance on plans that appear to have poor odds of implementation or success. ${ }^{158}$ Anecdotal evidence suggests that sometimes consultation processes do provide species with some benefit of the doubt, even in the face of political heat. ${ }^{159}$ That anecdotal evidence comports with a common perception among regulated groups that the ESA is zealously, and sometimes overzealously, implemented. Even if most academic observers are skeptical of the overall accuracy of that perception, its existence suggests that the wildlife agencies sometimes take protective stands despite uncertain information and heavy resistance. ${ }^{160}$

The overall track record of the ESA also suggests that the agencies sometimes take cautious approaches to plan success. While relatively few listed species have recovered, studies in the late 1990s concluded that few listed species went extinct, and most listed species, over time, showed gradual improvement. ${ }^{161}$ Multiple factors, some having little to do with management of plan uncertainty, may have

157. See, e.g., Blumm et al., supra note 153, at 734-35, 741-43 (describing such shifting standards).

158. See Cassidy, supra note 30 , at 179 \& n. 16 (listing cases).

159. See, e.g., Holly Doremus \& A. Dan Tarlock, Water War IN THE KLAMath BASIN: MACHO LAW, COMBAT BIOLOGY, AND DIRTY POLITICS 118-28 (2008) (describing partially successful efforts by FWS and NOAA Fisheries to implement protective plans in the Klamath Basin).

160. See supra note 153 and accompanying text.

161. See Jeffrey J. Rachlinski, Noah by the Numbers: An Empirical Evaluation of the Endangered Species Act, 82 CORNELl L. REV. 356 (1997) (book review). Some species, however, have continued to decline despite longstanding regulatory coverage. See, e.g., Blumm et al., supra note 153 (describing continuing difficulties with Columbia Basin salmon).

The recovery struggles also may derive from causes other than approaches to planning uncertainty. The recovery planning provisions are weak. See Federico Cheever, Recovery Planning, the Courts and the Endangered Species Act, 16 NAT. RESOURCES \& ENV'T 106, 108 (2001) ("Courts have been universally unwilling to order agencies to undertake recovery actions."). The services also have adhered to regulations that, according to commentators and several appellate courts, illegally read key habitat and recovery protections out of the Act. See Gifford Pinchot Task Force v. U.S. Fish \& Wildlife Serv., 378 F.3d 1059, 1069-71 (9th Cir. 2004) (rejecting the "adverse modification" definition as inconsistent with the statute); 50 C.F.R. $\$ 402.02$ (2008) (defining "destruction or adverse modification" and "jeopardy"); Houck, supra note 130, at 298-301; Rohlf, supra note 140, at 118-19. 
contributed to those successes, but they would have been unlikely if the agencies were as consistently tolerant of plan failure as some implementation critiques seem to suggest. ${ }^{162}$ Considering the informational shortfalls faced by agency staff, the budgetary restrictions under which they operate ${ }^{163}$ and the commonly intense resistance to protective measures-resistance that comes from outside the agencies and, often, from within-that modest evidence of success begins to seem impressive. ${ }^{164}$ Protection levels fall well short of many observers' expectations, and clearer and more protective standards might produce substantial improvement. But it is unlikely that ESA implementation could have achieved any success at all if agency staff did not sometimes feel empowered to demand assurance that plans will succeed, and did not sometimes perceive themselves to be prohibited from adopting plans that probably would not work.

\section{National Environmental Policy Act}

While CAA and ESA implementation exemplify approaches largely based on internal guidance and agency staff discretion, National Environmental Policy Act (NEPA) implementation illustrates the possibility of a different evolution. ${ }^{165}$ As in fishery management, NEPA's probability standards have been articulated almost exclusively by judges. Those standards are superficially strict; they facilitate different outcomes in some circumstances, and those changes illustrate their value. Nevertheless, weaknesses in those standards also illustrate some of the problems that arise when probability standards must be created and enforced entirely by the judiciary.

One might wonder why NEPA would necessitate a probability standard. NEPA, according to the standard characterization, "simply guarantees a particular procedure, not a particular result," and once an

162. See supra notes 128-131 and accompanying text (explaining the central importance the Act places on planning).

163. See Doremus, supra note 154 , at 64 (describing congressional attempts to undercut ESA implementation through low appropriations).

164. See id. at 62; Houck, supra note 130 . In a passage that reflects common academic perceptions of ESA implementation, Doremus writes:

Under the intense pressure that has been the norm for the ESA, they will seek out any flexibility the statute allows, and exploit it to deflect controversy. They will seize any opportunity to defer controversial decisions into the future, delegate those decisions to others, optimistically interpret data, and assume that uncertain or as yet unproven initiatives will rescue disappearing species.

See Doremus, supra note 154, at 62.

165. 42 U.S.C. $\S \S 4321-4370(f)$ (2006). 
agency prepares a legally adequate environmental impact statement (EIS), it may pursue whatever substantive outcomes it pleases. ${ }^{166}$ In practice, however, agencies usually attempt to comply with NEPA not by preparing EISs but by preparing environmental assessments and adopting "Findings of No Significant Impact" (FONSI), which they can legally adopt only if their projects will not create significant environmental impacts. ${ }^{167}$ To avoid creating such significant impacts, agencies often rely on mitigation measures, which usually are plans for future action. ${ }^{168}$ In practice, therefore, NEPA often creates a planning process somewhat like that of the CAA or the Magnuson-Stevens Act: it requires ex ante plans designed to prevent significant environmental impacts, and the legality of approval decisions is contingent upon expectations about those plans' success. ${ }^{169}$

As in other areas of environmental planning, the success of those plans is often uncertain. They may involve untested environmental strategies, rely on uncertain funding, or depend upon action by reluctant permittees. ${ }^{170}$ Rarely will plan implementation be checked; NEPA establishes no verification requirements. ${ }^{17}$ Substantial questions, therefore, often exist about whether mitigation measures will actually work, or whether they will just serve as convenient excuses to avoid the expense of EIS preparation. ${ }^{172}$ The few studies to examine the effectiveness of mitigation measures are "not encouraging": "fewer than one out of three verifiable predictions correctly forecast both the direction and the approximate magnitude of the environmental impact, while most predictions were simply unverifiable, either through fundamental imprecision or for lack of follow up data.",173

166. Ohio Forestry Ass'n v. Sierra Club, 523 U.S. 726, 737 (1998).

167. See Bradley C. Karkkainen, Whither NEPA?, 12 N.Y.U. ENVTL. L.J. 333, 347-48 (2004) (documenting the prevalence of FONSIs).

168. See id, at 348; Bradley C. Karkkainen, Toward a Smarter NEPA: Monitoring and Managing Government's Environmental Performance, 102 CoLUM. L. REv. 903, 932-38 (2002).

169. See Karkkainen, supra note 168 , at $906-08$. The primary difference is that NEPA's outcome standards are qualitative and amorphous.

170. See id. at 926-27 (describing the uncertainty of NEPA required predictions).

171. Karkkainen, supra note 167 , at 344.

172. See McGarity, supra note 30 , at $577-78$ (explaining why mitigation measures are not always implemented).

173. Karkkainen, supra note 168, at 928; see Paul J. Culhane, The Precision and Accuracy of U.S. Environmental Impact Statements, 8 ENVTL. MONTTORING \& ASSESSMENT 217, 235-36 (1987) (concluding that few predictions in a sample of EISs were demonstrably wrong, but that many predictions were not amenable to verification). 
Despite that uncertainty, neither the statute itself nor the Council on Environmental Quality's (CEQ) implementing regulations say how certain a lead agency should be that its mitigation measures will succeed. The CEQ's regulations say nothing more. In fact, neither the statute nor the CEQ's implementing regulations even refer to mitigated FONSIs, which arose as an invention of implementing agencies and received their legal stamp of approval from the courts. ${ }^{174}$

Filling this void, the courts put forth their own standard. It appears protective: agencies must "convincingly establish" that mitigation measures will succeed in reducing impacts to a less than significant level, and if "substantial questions" about the measures' effectiveness remain, EIS preparation is mandatory. ${ }^{175}$ Accordingly, courts have rejected reliance upon inchoate or speculative mitigation measures ${ }^{176}$ or upon mitigation measures whose effectiveness, even if implemented, is unknown. ${ }^{177}$ They similarly rejected reliance on measures demonstrably unlikely to be enforced, and demanded "more than mere vague statements of good intentions.",178 They have not

174. See Karkkainen, supra note 168 , at $944-45$ ("[T] $]$ he mitigated FONSI exists in a legal gray zone, generally accepted by the courts but without the safe harbor protection of explicit statutory or regulatory authorization or standards."). The CEQ did attempt to partially address the issue in one of its first guidance documents, where it sought to allow reliance on mitigation measures "only if they are imposed by statute or regulation, or submitted by an applicant or agency as part of the original proposal." Forty Most Asked Questions Concerning CEQ's National Environmental Policy Act Regulations, 46 Fed. Reg. 18,026, 18,038 (Mar. 23, 1981) (codified as amended at 40 C.F.R. pts. 1500-08). Agencies and courts have generally rejected that guidance. Albert I. Herson, Project Mitigation Revisited: Most Courts Approve Findings of No Significant Impact Justified by Mitigation, 13 ECOLOGY L.Q. 51, 51-52 (1986).

175. Conner v. Burford, 848 F.2d 1441, 1450 (9th Cir. 1988); Cabinet Mountains Wilderness/Scotchman's Peak Grizzly Bears v. Peterson, 685 F.2d 678, 682 (D.C. Cir. 1982). See generally Am. Bird Conservancy, Inc. v. FCC, 516 F.3d 1027, 1033-34 (D.C. Cir. 2008) (holding that where an action's environmental consequences are uncertain but may be significant, an EIS must be prepared).

176. E.g., O'Reilly v. U.S. Army Corps of Eng'rs, 477 F.3d 225, 234 (5th Cir. 2007) ("[T]he EA provides only cursory detail as to what those measures are and how they serve to reduce those impacts to a less-than-significant level .... [T] he feasibility of the mitigation measures is not self-evident ...."); Conner, 848 F.2d at 1450 (rejecting reliance on unspecified regulatory measures).

177. E.g., Blue Mountains Biodiversity Project v. Blackwood, 161 F.3d 1208, 1214 (9th Cir. 1998); Idaho Sporting Cong. v. Thomas, 137 F.3d 1146, 1151 (9th Cir. 1998) ("Without analytical data to support the proposed mitigation measures, we are not persuaded that they amount to anything more than a 'mere listing' of good management practices."); The Steamboaters v. FERC, 759 F.2d 1382, 1394 (9th Cir. 1985) ("The problem here is that FERC fails to explain specifically how the conditions would mitigate the impact of the project. Further, the proposed conditions provide only general guidelines."); Found. for N. Am. Wild Sheep v. U.S. Dep't of Agric., 681 F.2d 1172, $1180-81$ (9th Cir. 1982).

178. Audubon Soc'y of Cent. Ark. v. Dailey, 977 F.2d 428, 435-36 (8th Cir. 1992) (internal quotations omitted) (rejecting reliance on a mitigation measure where "evidence... 
required absolute certainty or any binding legal commitment to mitigation measures; generally, "the mitigating measures need not be a condition of the permit ... nor even a contractual obligation.,"179 But the general judicial trend seems to be toward at least reciting a rule demanding a moderately high level of assurance. The United States Court of Appeals for the Ninth Circuit's recent decision in National Parks \& Conservation Ass' $n$ v. Babbitt, in which it rejected reliance on mitigation measures that the Park Service asserted "could" work, exemplifies that standard approach. ${ }^{180}$

For several reasons, however, that standard, as applied, contains less stringency than meets the eye. First, courts often find mitigation measures to be sufficient simply because the lead agency could enforce them. ${ }^{181}$ But a finding of enforceability does not ensure that a violation will be enforced, or that a mitigation measure will actually be fully and successfully implemented. ${ }^{182}$ Enforcement requires time and money and means imposing burdens the lead agency may have no wish to impose, particularly if, as is often the case, the lead agency has a weak institutional commitment to environmental protection. ${ }^{183}$ The agency also will have disincentives even to discover implementation problems, for if violations are found, or if the mitigation measure is implemented but significant adverse impacts nevertheless result, the agency's own original decision will appear questionable. For these reasons, Thomas McGarity has charged that "[i]f the agency may ignore its enforcement obligations with impunity, and if adversely affected members of the public are not empowered to enforce the conditions, the EISs are inadequate and the FONSIs are phantoms." ${ }^{\prime 184}$

More fundamentally, some NEPA decisions dilute the standard by conflating two separate inquiries. In deciding whether the agency properly declined to prepare an EIS, courts generally must ask whether the agency took an action contrary to law. Specifically, the court must

gave every reason to doubt" its enforceability); e.g., Nat'l Parks \& Conservation Ass'n v. Babbitt, 241 F.3d 722, 733-36 (9th Cir. 2001) (rejecting a FONSI where "uncertainty that exists as to whether the mitigation measures would work").

179. Audubon Soc'y of Cent. Ark., 977 F.2d at 436.

180. 241 F.3d at 734-35.

181. See McGarity, supra note 30 , at 597-99.

182. See id. at 601 (criticizing decisions that "were probably too solicitous of the agency when they failed to discount the benefits of stipulations and permit conditions by the very real probability that they would not be enforced").

183. See generally Calvert Cliffs' Coordinating Comm., Inc. v. U.S. Atomic Energy Comm'n, 449 F.2d 1109, 1112-15 (D.C. Cir. 1971) (concluding that NEPA was designed to force reluctant agencies to act).

184. McGarity, supra note 30, at 605. 
decide whether the agency declined to prepare an EIS despite the possibility of significant environmental impacts. The court must also ask whether the agency considered relevant factors and engaged in a reasoned inquiry. ${ }^{185}$ In theory, a court could answer the former question in the negative and the latter in the affirmative; an agency would act unlawfully if it approved a FONSI despite significant acknowledged uncertainties, even if it had engaged in careful discussion of those uncertainties. In practice, however, some courts appear to blend the two questions, finding that uncertainty is no bar to a FONSI as long as the uncertainty is carefully explored and discussed. ${ }^{186}$ That approach creates a fundamentally different, and substantially more failure-tolerant, standard.

While somewhat anomalous, that line of cases highlights a hazard inherent in leaving the formulation and application of probability standards entirely up to the judiciary. ${ }^{187}$ The process of developing such standards can force courts into uncomfortable territory. Those processes may be technically complex and laden with policy questions, which courts may be reluctant to resolve. While legal issues will arise, discerning the lines between technical analysis,

185. See 5 U.S.C. § 706(2) (2006); Motor Vehicle Mfrs. Ass'n v. State Farm Mut. Auto. Ins. Co., 463 U.S. 29, 42-43 (1983).

186. See, e.g., Greenpeace Action v. Franklin, 14 F.3d 1324, 1332-35 (9th Cir. 1992) (upholding a FONSI reliant upon mitigation measures, despite the lead agency's concession "that the effectiveness of the mitigation measures is uncertain," because "the record in this case reveals no complete failure to consider crucial factors"); North Carolina v. Hudson, 731 F. Supp. 1261, 1269-73 (E.D.N.C. 1990) (upholding a FONSI despite disagreement, which the lead agency appeared to concede was reasonable, from other agencies' experts about whether significant impacts would result from the project); see also Ohio Valley Envtl. Coal. v. Aracoma Coal Co., 556 F.3d 177, 205 (4th Cir. 2009) (upholding reliance on mitigation measures despite acknowledging that "support for [the lead agency's] claim that the proposed [mitigation] measures have good potential for success is admittedly limited").

187. Those cases have an important parallel, albeit from a slightly different context. In Baltimore Gas \& Electric Co. v. Natural Resources Defense Council, Inc., 462 U.S. 87 (1983), the Supreme Court upheld a decision to exclude uncertain impacts from evaluation largely because the uncertainty was candidly discussed. Baltimore Gas addressed the legality of the NRC's decision to prescribe, through rulemaking, a "zero-release" rule stating that individual EISs should not consider the possibility of releases of nuclear waste, on the theory that such releases would be prevented. Id. at 90-94. That was a dubious proposition. See discussion infra Part II.F. The Court acknowledged that "no one suggests that the uncertainties are trivial or the potential effects insignificant if time proves the zero-release assumption to have been seriously wrong." Baltimore Gas, 462 U.S. at 98 . But the Court upheld the rule, stating that "it simply cannot be said that the Commission ignored or failed to disclose the uncertainties surrounding its zero-release assumption." Id. at 100; see Daniel A. Farber, Confronting Uncertainty Under NEPA, 8 ISSUES IN LEGAL SCHOLARSHIP 17-18 (2009) (critiquing the Baltimore Gas decision). 
policy analysis, and legal analysis may be difficult. ${ }^{188}$ Courts also are likely to worry that in articulating too specific a standard, they will risk micromanaging agency procedural choices. ${ }^{189}$ Those constraints do not mean that judicially articulated NEPA standards lack meaning or value. In some cases, courts have invoked those standards to require EIS preparation, and those decisions create incentives that can help balance the overwhelming administrative convenience of paper mitigation measures. ${ }^{190}$ But courts may shy away from setting aggressive standards, or, as in the NEPA context, from carefully and consistently policing standards that do not come from Congress or from the agency itself. Deference, even where it is not appropriate, is likely to be quite common.

\section{E. Water Quality}

The Clean Water Act (CWA) relies upon a dual regulatory approach, in which technology-based controls complement a planningbased system. ${ }^{191}$ That planning system also contends with significant uncertainties. But compared to the statutes discussed so far, the CWA contains slightly stronger signals-albeit still weak ones-about how planning uncertainty should be managed. In an otherwise problematic regulatory system, those signals stand out as a positive feature worth imitating.

The CWA's planning-based system starts by requiring the states to develop water quality standards. ${ }^{192}$ States then must identify water bodies where technology-based point source controls will not be sufficient to ensure compliance with those standards, ${ }^{193}$ and the states also must engage in "continuing planning process[es]" designed to bring deficient areas into compliance. ${ }^{194}$ The CWA's primary planning mechanism is something known as a "total maximum daily load" (TMDL), which serves as a pollution budget for the impacted water body. ${ }^{195}$ TMDL-based regulation should, in theory, reach both point and nonpoint pollution sources, and thus the TMDL system should

188. See, e.g., Farber, supra note 187 , at 17-18 (criticizing the Supreme Court for conflating legal and technical issues in its Baltimore Gas decision).

189. Vt. Yankee Nuclear Power Corp. v. NRDC, 435 U.S. 519, 543-47 (1978).

190. See supra notes $175-178$ and accompanying text.

191. See Pronsolino v. Nastri, 291 F.3d 1123, 1126 (9th Cir. 2002); Olver A. HoucK, The Clean WATER ACT TMDL PROGRAM: LAW, Policy, AND IMPLEMENTATION 3 (1999).

192. 33 U.S.C. $\S 1313$ (b)-(c) (2006).

193. Id. $\S 1313(\mathrm{~d})(1)(\mathrm{A})$.

194. Id. $\S 1313(\mathrm{e})$; Pronsolino, 291 F.3d at 1128-29.

195. 33 U.S.C. $\S 1313(\mathrm{~d})(1)(\mathrm{C})$; Pronsolino, 291 F.3d at 1127-28. 
provide a valuable complement to the technology-based permit program, which reaches point sources alone. ${ }^{: 96}$ But in creating TMDLs and associated regulatory plans, water quality agencies must contend with significant uncertainties. Shortages of baseline data, complex and poorly understood contaminant pathways, and a variety of other complexities preclude agencies from knowing with certainty that their pollution budgets are right. ${ }^{197}$

The TMDL system has been heavily criticized as an incomplete planning approach. ${ }^{198}$ While generating lists of impaired water bodies and TMDLs for those bodies clearly is mandatory, the CWA does not fully specify how states are to translate those budgets into legal obligations. Some planning is required, ${ }^{199}$ and TMDLs should be considered when setting effluent limitations in point source permits. ${ }^{200}$ But, unlike the CAA, the CWA neither contains detailed standards explaining how the plans should be enforced nor empowers the EPA to reject plans and create its own enforceable substitutes. ${ }^{201}$ To add to the complications, the EPA and the states ignored even the clear and mandatory obligations for years. Until compelled to do so by environmental groups' lawsuits, the states generated few lists of impaired water bodies and hardly any TMDLs, and the EPA focused its attentions on implementing the CWA's point source controls. ${ }^{202}$ Consequently, the evolution of the program has lagged, and few states have turned TMDLs into effective regulatory programs.

Despite those flaws, section 1313(d)(1)(C) does contain one feature worth imitating, albeit in strengthened form. It states that each

196. See David S. Baron, Water Quality Standards for Rivers and Lakes: Emerging Issues, 27 ARIZ. ST. L.J. 559, 559-60 (1995).

197. HouCK, supra note 191, at 58-59, 171, 195; COMM. To ASSESS THE SCIENTIFIC Basis of the TOtal MaXimum Daily load APPROACH to Water POllution Reduction, NAT'L RESEARCH COUNCIL, ASSESSING THE TMDL APPROACH TO WATER QuALITY MANAGEMENT 2, 20, 28-30 (2001) [hereinafter TMDL APPROACH]. The NRC Committee argued, however, that these uncertainties can and should be managed through statistical uncertainty analyses. TMDL APPROACH, supra, at 10, 73-76.

198. See, e.g., HouCK, supra note 191, at 206-07. Houck also questions whether even a complete planning approach would be as effective as alternative regulatory systems.

199. 33 U.S.C. $\$ 1313(e)$.

200. Id. \$1341(a) (requiring that federal licensees and permittees comply with "all applicable provisions" of section 1313, among other sections); id. §1313(d)(4) (providing water quality compliance requirement for NPDES permits); 40 C.F.R. $\S 122.44$ (d)(1)(vii)(B) (2008).

201. See HoucK, supra note 191, at 206-07 (contrasting the programs). The EPA can reject TMDLs and promulgate its own substitutes. 33 U.S.C. $§ 1313$ (d)(2). However, it has limited power to translate TMDLs into constraints on individual sources. See Pronsolino v. Nastri, 291 F.3d 1123, 1140 (9th Cir. 2002).

202. HoucK, supra note 191, at 49-64; see Baron, supra note 196, at 578. 
TMDL "shall be established at a level necessary to implement the applicable water quality standards with seasonal variations and a margin of safety which takes into account any lack of knowledge concerning the relationship between effluent limitations and water quality."203 In other words, to account for uncertainty, the budget must overshoot the mark. Section 1313 does not state how much of a buffer TMDLs should provide; that choice is left to agency discretion. The EPA also has not fleshed out that requirement with more specific regulations, though it has promulgated some general guidance, and instead has left its decisionmakers broad flexibility to select their margins on a project-by-project basis. ${ }^{204}$ But even if substantial flexibility remains, the pertinent statutory language indicates that if, as in Daley, the agency's best estimate is that achieving the TMDL's limits would not produce compliance, the TMDL is not legal. That small bit of direction sets the CWA apart from the Magnuson-Stevens Act, the CAA, and NEPA; none of those statutes explicitly require an analogous approach. ${ }^{205}$

Because the TMDL program lay dormant for decades, implementation remains in the early stages, and few cases evaluate the implications of this margin-of-safety requirement. Evidence from agency decisions is also scant, and one study of early TMDLs found that the states did little to explain their margins of safety and sometimes simply ignored the requirement. ${ }^{206}$ Even with strict observance of the margin-of-safety requirement, the many other weaknesses in the statutory structure mean that this provision alone will never be enough to ensure an effective planning approach. Nevertheless, two judicial decisions do suggest it can produce significant benefits if integrated into a more robust planning scheme.

203. 33 U.S.C. $\S 1313(d)(1)(C)-(D)$.

204. See 40 C.F.R. $\S 130.7$ (c) (echoing the statutory language); EPA, GUIDANCE FOR Water Quality-Based Decisions: The TMDL Process 15 (1991), available at http://www.epa.gov/waterscience/models/library/SASD0109.pdf [hereinafter EPA, GuIDANCE FOR WATER QUALITY-BASED DECISIONS] (stating that larger margins of safety are "appropriate" where uncertainties are substantial, but not establishing any requirement); EPA, Guidelines for Reviewing TMDLs Under Existing Regulations Issued in 1992, http://www.epa.gov/owow/tmdl/guidance/final52002.html (last visited Aug. 29, 2009) (providing that margins can be included in a variety of ways, including adopting conservative modeling assumptions). In its 1999 report, the NRC criticized common approaches to setting margins of safety as "arbitrarily selected." TMDL APPROACH, supra note 197, at 74.

205. The CAA does require margins of safety in the NAAQS, but those margins are present to address uncertainties about health needs, not uncertainties about planning outcomes. See supra note 82 and accompanying text.

206. HouCK, supra note 191, at 108. 
The first, an unpublished decision by the United States District Court for the Western District of Washington in Dioxin/Organochlorine Center v. Rasmussen, ${ }^{207}$ involved an industry challenge to an allegedly overprotective TMDL. Citing the "margin of safety" language, the court rejected the challenge. Its reasoning is not entirely clear, but the court may have viewed that language as insulating the EPA against charges that it was irrationally overregulating. ${ }^{208}$ That may seem like a small point, but challenges against alleged environmental overprotection are common, ${ }^{209}$ and some environmental managers believe they cannot approve anything more stringent than the most lenient plan that might succeed. ${ }^{210}$ Empowering agencies to take a more cautious approach can therefore change outcomes.

In the second case, Natural Resources Defense Council, Inc. v. Muszynski, environmental groups challenged the EPA's approval of a New York State TMDL with an allegedly underprotective ten percent margin of safety. ${ }^{21}$ While NRDC argued that the ten percent margin was inadequately explained and inconsistent with relevant guidance and expert testimony, the EPA prevailed; both the United States District Court for the Southern District of New York and the Second Circuit concluded that the EPA had discretion to exercise professional judgment in selecting the appropriate margin of safety. ${ }^{212}$ That outcome suggests that having a margin-of-safety requirement will not always lead to a buffer that environmental advocates view as sufficient. If the agency wants to select a thin margin of safety and can reasonably explain that choice, courts probably will defer. Nevertheless, that New York even included a margin of safety in its TMDL, and that New York and the EPA provided explanations for its sufficiency, creates a striking contrast with Environmental Defense v. EPA, the CAA case previously

207. No. C.93-33D, 1993 WL 484888 (W.D. Wash. Aug. 10, 1993), aff'd by Dioxin/Organochlorine Ctr. v. Clarke, 57 F.3d 1517 (9th Cir. 1995). The appellate decision does not discuss the margin of safety language.

208. Id. at *6, *8.

209. E.g., Fishermen's Dock Coop., Inc. v. Brown, 75 F.3d 164 (4th Cir. 1996).

210. E.g., Fine \& Owen, supra note 30, at 959; see also Rohlf, supra note 140, at 14142 (describing the Department of the Interior's policy of allocating the "cushion"-in other words, deliberately giving away the margin of safety-to endangered species-impacting projects).

211. 268 F.3d 91 (2d Cir. 2001).

212. Id. at 102-03; NRDC v. Fox, 93 F. Supp. 2d 531, 553-54 (S.D.N.Y. 2000) ("[A]bsent more specific guidance from Congress-EPA is in the best position to determine, in its professional judgment, whether a proposed TMDL contains an adequate margin of safety."). 
discussed. $^{213}$ There, the facts strongly suggest that New York's SIP amendment contained no margin of safety. But because the CAA says hardly anything about safety margins or success odds, the requisite level of assurance escaped discussion and review. ${ }^{214}$ In TMDL approval processes, by contrast, such disappearance would be legally suspect. ${ }^{215}$ The states and the EPA must include and coherently explain at least some margin, and those requirements should create incentives toward developing TMDLs that are likely to succeed.

\section{F. Nuclear Waste ${ }^{216}$}

Nuclear waste policy exemplifies a somewhat different approach to planning uncertainty. Planning again is critical, and planners must confront significant unknowns. ${ }^{217}$ As in most other areas of environmental law, Congress has provided little direct guidance about how plans should manage uncertainties. But agencies and an unusual participant - the National Academy of Sciences (NAS)-have engaged the issue, and their discussions have produced a numeric probability standard. The process of reaching that standard has been far from ideal, and it illustrates some of the perils of developing probability standards after a project is under consideration, rather than trying to create a generally applicable standard in advance of particular proposals. Nevertheless, the overall approach in some ways represents an improvement over the hidden approaches used elsewhere, and it illustrates some of the positive functions a regulatory probability standard can serve.

Perhaps no area of environmental policy relies as heavily upon ex ante planning as nuclear waste management. Some nuclear wastes have long half-lives, ${ }^{218}$ and consequently, as the D.C. Circuit recently put it, "[r]adioactive waste and its harmful consequences persist for time spans seemingly beyond human comprehension.".19 One

213. 369 F.3d 193 (2d Cir. 2004); see supra notes 117-124 and accompanying text.

214. See supra notes 117-124 and accompanying text.

215. See EPA, GUIDANCE FOR WATER QUALITY-BASED DECISIONS, supra note 204, ch. 3 (describing margin of safety selection as a standard step in the TMDL development process).

216. From 2004 until 2007, I helped represent Nevada in its opposition to the Yucca Mountain repository. Although this Part draws upon that experience, the points raised are my own except where otherwise cited.

217. See generally UNCERTAINTY UNDERGROUND: YUCCA MOUNTAIN AND THE NATION'S High-LEVEL NUCLEAR WASTE (Allison M. Macfarlane \& Rodney C. Ewing eds., 2006).

218. Id. at 6 .

219. NEI v. EPA, 373 F.3d 1251, 1258 (D.C. Cir. 2004). 
therefore cannot reasonably assume that present social or political institutions will survive long enough to adjust waste containment systems, ${ }^{220}$ and the selection of effective waste management strategies instead depends upon modelers' predictive capacities. ${ }^{221}$ Predictions of plan success also have short-term consequences, for the nuclear industry cannot function indefinitely without a plan for waste management. ${ }^{222}$ Nuclear power's viability therefore may be partially contingent upon our ability to generate waste management plans that seem, based on current projections, highly likely to contain wastes for millennia-or our willingness, for the sake of present benefit, to accept plans with a substantial possibility of future failure.

Those policy choices have unfolded through a complex legal and political process. In 1982, Congress enacted the Nuclear Waste Policy Act (NWPA), ${ }^{223}$ which assigns the federal government responsibility for managing the nation's high-level nuclear waste and directs the Department of Energy (DOE) to select disposal sites. ${ }^{224}$ A site selection process and subsequent legislation narrowed DOE's evaluative focus to Yucca Mountain in Nevada, ${ }^{225}$ and in 2003, DOE selected Nevada's Yucca Mountain as its site. ${ }^{226}$ DOE's decision triggered an obligation for DOE to apply to the Nuclear Regulatory Commission (NRC) for an operating license, which DOE did in June, $2008{ }^{227}$ The application should specify measures, including

220. See 42 U.S.C. § 10101(9) (2006) (defining "disposal" as emplacement "with no foreseeable intent of recovery"); COMM. ON TECHNICAL BASES FOR YUCCA MOUNTAIN Standards, Nat'l Research Council, TeChNical Bases for Yucca Mountain STANDARDS 8 (1995) [hereinafter TECHNICAL BASES].

221. See Environmental Standards for the Management and Disposal of Spent Nuclear Fuel, High-Level and Transuranic Radioactive Wastes, 50 Fed. Reg. 38,066, 38,070 (Sept. 19, 1985) (codified as amended at 40 C.F.R. pt. 191) ("Standards must be implemented in the design phase for these disposal systems because active surveillance cannot be relied upon over such periods.").

222. Since 1977, the NRC has asserted that "it would not continue to license reactors if it did not have reasonable confidence that the waste can and will in due course be disposed of safely." Thomas A. Cotton, Nuclear Waste Story: Setting the Stage, in UNCERTAINTY UNDERGROUND: YUCCA MOUNTAIN AND THE NATION'S HIGH-LEVEL NUCLEAR WASTE, supra note 217 , at 31 (internal quotations omitted).

223. Pub. L. No. 97-425, 96 Stat. 2201 (1982) (codified as amended at 42 U.S.C. $\S \S 10,101-10,270(2006))$.

224. 42 U.S.C. $\$ 10,132$; see NEI, 373 F.3d at 1258-59; NRDC v. EPA, 824 F.2d 1258, 1262-63 (1 st Cir. 1987) (describing the process originally set out by the NWPA).

225. NEI, 373 F.3d at 1260; see Robert J. Cynkar, Dumping on Federalism, 75 U. COLO. L. REV. 1261, 1271 (2004).

226. NEI, 373 F.3d at 1260-61.

227. 42 U.S.C. $\S 10,134$; Office of Civilian Radioactive Waste Mgmt., Dep't of Energy, Repository Licensing Overview, htt://www.ocrwm.doe.gov/factsheets/ doeymp0111.shtml (last visited Sept. 1, 2009). 
engineering controls and geologic containment systems that the DOE will rely upon to isolate the waste. Though not labeled as such, the application is basically a waste containment plan. ${ }^{228}$ In evaluating that plan, the NRC will act much like the EPA when it reviews a state's SIP or NOAA Fisheries when it reviews a fishery management plan. Using modeled simulations of the plan's performance, the NRC will determine whether the plan will assure compliance with health and safety standards developed by the EPA and by the NRC itself. ${ }^{229}$

Just as with fisheries and air quality planning, the performance of a nuclear waste disposal system cannot be predicted with certaintyexcept, of course, if a system would be sure to fail. ${ }^{230}$ Predicting the course of human events for the next million years is impossible, and in order to even perform an analysis, simplifying assumptions are unavoidable. ${ }^{231}$ Many of the DOE's proposed engineering controls are novel and lack natural analogs, and while there is general agreement that the engineered systems eventually will fail, estimates of the timing of that failure vary widely. ${ }^{232}$ The performance of a natural containment system is somewhat easier to predict; unlike engineers, geologists and climatologists can draw upon the past in predicting the future, and in those fields predictions spanning thousands of years are common. ${ }^{233}$ Nevertheless, climate changes, volcanic activity, earthquakes, and other variables complicate efforts to predict future outcomes, as can incomplete understanding of a site's geology and

228. See Office of Civilian Radioactive Waste Mgmt., Dep't of Energy, Elements of the License Application, http://www.ocrwm.doe.gov/fact/contents_of_the_license_ application.shtml (last visited Sept. 1, 2009) (explaining the contents of the license application). The license application is available online. NRC, DOE's License Application for a High-Level Waste Geologic Repository at Yucca Mountain, http://www.nrc.gov/waste/ hlw-disposal/yucca-lic-app.html (last visited Sept. 1, 2009).

229. See Energy Policy Act of 1992, Pub. L. No. 102-486, § 801, 106 Stat. 2776, 2921-23 (1992) (codified as amended at 42 U.S.C. § 10,141); Chris Whipple, Performance Assessment: What Is It and Why Is It Done, in UNCERTAINTY UNDERGROUND: YUCCA MOUNTAN AND THE NATION's HIGH-LEVEL NUCLEAR WASTE, supra note 217, at 57-70.

230. See TECHNICAL BASES, supra note 220 , at 1 ("'A] performance must contend with substantial uncertainties ...."). See generally John Lemons, Uncertainties in the Disposal of High-Level Nuclear Waste, in SCIENTIFIC UNCERTAINTY AND ENVIRONMENTAL PROBLEM SOLVING, supra note 111, at 55; UNCERTAINTY UNDERGROUND: YUCCA MOUNTAIN AND THE NATION'S HIGH-LEVEL NUCLEAR WASTE, supra note 217.

231. See TeCHNICAL BASES, supra note 220, at 9-11.

232. See Allison C. Macfarlane, Technical Policy Decision Making in Siting a HighLevel Nuclear Waste Repository, in UNCERTAINTY UNDERGROUND: YUCCA MOUNTAIN AND THE NATION'S HIGH-LEVEL NUCLEAR WASTE, supra note 217, at 89.

233. See TECHNICAL BASES, supra note 220, at 9. 
hydrology. ${ }^{234}$ The models themselves add additional uncertainty, for their complexity minimizes transparency and can mask design flaws. ${ }^{235}$ Despite these uncertainties, predicting site performance is more than guesswork. For Yucca Mountain, at least, the NAS has concluded that the natural and engineering uncertainties, though real, are analytically manageable, and that system performance can plausibly be assessed over hundreds of thousands of years. ${ }^{236}$ But modelers will not be able to precisely predict future exposure to radioactive releases from the site, and instead will use Monte Carlo analyses to predict a range of possible outcomes. ${ }^{237}$ Someone therefore must decide how to compare those outcomes to the safety standard. Depending upon the leniency of the standard and the final predictions of the models (and, of course, congressional and presidential decisions), that choice could prove outcome-determinative. ${ }^{238}$

As in most other areas of environmental law, Congress has provided little guidance on probability standards. The Atomic Energy Act of 1954 (AEA), which ushered in the era of nuclear regulation, simply instructs the Atomic Energy Commission to promote nuclear power while providing the public with "adequate protection"-a term the AEA did not define. ${ }^{239}$ The NWPA, though centrally focused upon waste management, is only slightly less open-ended. The NWPA demands "reasonable assurance that the public and the environment will be adequately protected from the hazards posed by high-level radioactive waste and such spent nuclear fuel as may be disposed of in a repository."240 In demanding "reasonable assurance," Congress invoked a term of art; the NRC had traditionally required that licensees

234. See Whipple, supra note 229, at 62-67; Lemons, supra note 230, at 59-64. See generally UNCERTAINTY UNDERGROUND: YUCCA MOUNTAIN AND THE NATION'S HIGH-LEVEL NuCLEAR WASTE, supra note 217, at 105-282. The uncertainties at Yucca Mountain are compounded by the uniqueness of the site. Most other countries are proposing to dispose their nuclear waste below the water table. Macfarlane, supra note 232, at 87. Yucca Mountain therefore cannot easily be compared to other proposed repositories.

235. Whipple, supra note 229 , at 64-67.

236. See TeChNiCAl Bases, supra note 220, at 1, 9. But see NEI v. EPA, 373 F.3d 1251,1269 (D.C. Cir. 2004) (noting EPA's disagreement with this conclusion).

237. Whipple, supra note 229 , at 60,65 . For an explanation of Monte Carlo analyses, see generally Susan R. Poulter, Monte Carlo Simulation in Environmental Risk Assessment-Science, Policy and Legal Issues, 9 RISK 7 (1998).

238. See Whipple, supra note 229 , at 61 , reproducing a chart, which a DOE contractor created in 2001, showing predicted performance as a function of time. The differences among the fifth percentile, median, mean, and ninety-fifth percentile are substantial.

239. Atomic Energy Act of 1954, Pub. L. No. 83-703, § 182(a), 68 Stat. 919, 954 (codified as amended at 42 U.S.C. § 2232(a) (2006)); see Richard Goldsmith, Regulatory Reform and the Revival of Nuclear Power, 20 HOFSTRA L. REV. 159, 162 (1991).

240. 42 U.S.C. $\$ 10131(b)(1)$. 
provide "reasonable assurance" that public health and safety would be protected. ${ }^{241}$ Nevertheless, that term of art is not much clearer than "adequate protection"-it signals that absolute assurance is not necessary, but otherwise invites but does not substantially constrain regulatory judgment. ${ }^{242}$ Consequently, neither statutes nor the NRC's traditional standards say whether the NRC should use a ninety-five percent confidence interval, the median, the mean, some other numeric measure, or a qualitative standard more specific than "reasonable assurance."

While Congress provided little guidance about the requisite level of assurance, the Energy Policy Act of 1992 prescribed a specific process for developing the health and safety standards against which Yucca Mountain would be evaluated. ${ }^{243}$ That process, in combination with ongoing EPA deliberations, in turn allowed a dialogue about the appropriate treatment of plan uncertainty. ${ }^{244}$ Rather than simply asking the EPA and the NRC to generate standards, Congress directed the NAS to prepare recommendations on the technical bases for the Yucca Mountain standards, and ordered the EPA to generate standards "based

241. See Power Reactor Dev. Co. v. Int'l Union of Elec., Radio \& Mach. Workers, 367 U.S. 396, 406-07 (1961); Disposal of High-Level Radioactive Wastes in Geologic Repositories Technical Criteria, 48 Fed. Reg. 28,194, 28,202, 28,204 (June 21, 1983) (codified as amended at 10 C.F.R. pt. 64).

242. The NRC has sometimes suggested that "reasonable assurance" is a highly protective standard, which requires not just that applicants demonstrate compliance with relevant numeric standards but also that their demonstration pass a supplemental qualitative judgment test. Disposal of High-Level Radioactive Wastes in Geologic Repositories Technical Criteria, 48 Fed. Reg. at 28,202, 28,204. The NRC has declined to affix any particular percentage to the reasonable assurance concept, however, and its definition of the concept deliberately leaves substantial flexibility for discretionary judgment. See id.

243. Energy Policy Act of 1992, Pub. L. No. 102-486, § 801, 106 Stat. 2776, 2921-23 (1992) (codified as amended at 42 U.S.C. $\S 10,141(2006)$ ).

244. Before enactment of the Energy Policy Act of 1992, the EPA already had created numeric standards for both containment of and exposure to nuclear waste. It also established secondary probability standards, both qualitative and quantitative, which specified the requisite likelihood of achieving compliance with the containment and exposure standards. Environmental Standards for the Management and Disposal of Spent Nuclear Fuel, HighLevel and Transuranic Radioactive Wastes, 50 Fed. Reg. 38,066, 38,085 (Sept. 19, 1985) (codified as amended at 40 C.F.R. pt. 91). In some standards, the EPA specified required percentage assurances that particular values would not be exceeded. See 40 C.F.R. $\S 191.13$ (2008). However, for other measures, it recommended using a "best estimate," which it described as "the mean or the median of the appropriate distribution, whichever is higher." Id. $\S 191$ app. B, 50 Fed. Reg. at 38,088. The EPA's overarching qualitative standard required a "reasonable expectation," which the EPA described as somewhat less stringent than a "reasonable assurance" of compliance with the numeric probability standards. 50 Fed. Reg. at 38,076. The EPA also required "assurance" measures, which it described as supplemental controls to account for uncertainties in the numeric predictions. See 40 C.F.R. $§ 191.14 ; 50$ Fed. Reg. at 38,079. 
upon and consistent with the findings and recommendations of the National Academy of Sciences."245 In 1995, the NAS completed its study, which, among many other recommendations, identified the mean as the appropriate probability standard. ${ }^{246}$

That recommendation became significant when, after a series of failed rulemaking efforts, the EPA proposed a different approach ${ }^{247}$ In a 2005 draft rule, the EPA proposed to select the mean as a pre-10,000 year measure and the median, which could be a dramatically lower number ${ }^{248}$ and therefore would effectively create a more permissive standard, as its longer-term measure. ${ }^{249}$ A vigorous dialogue ensued, with many comments contesting that proposal ${ }^{250}$ and public reports considering its viability. ${ }^{251}$ In its final rulemaking, the EPA abandoned the median and returned to the mean as its sole probability standard. ${ }^{252}$

That process leaves something to be desired. Ideally, the selection of probability standards - and other aspects of a safety standard-would precede the selection of a specific site to be evaluated. Once a particular site is chosen, political pressure naturally will build to make the evaluative system fit the site rather than the

245. Energy Policy Act $\S 10,141$.

246. TECHNICAL BASES, supra note 220, at 123.

247. The EPA generated its first standard in the 1980s, and, on other grounds, several petitioners successfully challenged the EPA's rule. NRDC v. EPA, 824 F.2d 1258 (1st Cir. 1987). In 2001, after Yucca Mountain became the DOE's primary focus and Congress had enacted the Energy Policy Act, the EPA tried again. Public Health and Environmental Radiation Protection Standards for Yucca Mountain, NV, 66 Fed. Reg. 32,074 (June 13, 2001) (codified as amended at 40 C.F.R. pt. 197). This time, it selected the arithmetic mean as its probability standard, meaning that average predicted future exposure levels or environmental concentrations would be compared to the relevant standards. Id. at 32,125. That rule also was set aside, again on other grounds, setting the stage for the 2005 proposed rule. NEI v. EPA, 373 F.3d 1251, 1257 (D.C. Cir. 2004).

248. The KeYstone CTR., Nuclear Power JoINT FaCt-Finding 71 (2007) (noting that the mean "could be 3 or more times higher" than the median). The difference exists because the modeling projections do not produce a classic "normal distribution." Instead, the projections show some resemblance to a "power law" distribution, which includes more high values than a bell curve. See generally Daniel A. Farber, Probabilities Behaving Badly: Complexity Theory and Environmental Uncertainty, 37 U.C. DAVIS. L. REV. 145 (2003).

249. Public Health and Environmental Radiation Protection Standards for Yucca Mountain, NV, 70 Fed. Reg. 49,014, 49,041-46 (proposed Aug. 22, 2005) (to be codified at 40 C.F.R. pt. 197).

250. See Office of Radiation \& Indoor Air, Response to Comments, Amendments to the Public Health and Environmental Radiation Protection Standards for Yucca Mountain, Nevada 201-19, http://www.epa.gov/rpdweb00/docs/yucca/rtc-document-final.pdf (last visited Sept. 7, 2009) (providing comments on the mean/median choice and the EPA's responses to those comments).

251. THE KEYSTONE CTR., supra note 248, at 71 .

252. Public Health and Environmental Radiation Standards for Yucca Mountain, Nevada, 73 Fed. Reg. 61,256, 61,261 (Oct. 15, 2008) (to be codified at 40 C.F.R. pt. 197). 
underlying public safety goal. ${ }^{253}$ Instead, a combination of Congressional intervention, agency choices, and litigation outcomes delayed finalization of the safety standards, leaving the EPA to generate those safety standards in full awareness that they could be outcome determinative, not only for Yucca Mountain, ${ }^{254}$ but also for a nuclear revival, ${ }^{255}$ for the NRC's and the DOE's continued bureaucratic importance, ${ }^{256}$ and for the federal treasury. ${ }^{257}$ Also, ideally the dialogue surrounding that choice would be consistently robust and informed, and would involve participants relying on their core areas of expertise. Here, however, Congress delegated a mixture of science and policy questions to the NAS, ${ }^{258}$ which then provided, with hardly any explanation, a policy-laden recommendation for a probability standard. ${ }^{259}$ The EPA, which theoretically has more policy expertise than the NAS, disputed that recommendation primarily on flawed

253. See William M. Murphy, Regulating the Geologic Disposal of High-Level Nuclear Waste at Yucca Mountain, in UNCERTAINTY UNDERGROUND: YUCCA MOUNTAIN AND THE NATION's HiGH-LEVEL NUCLEAR WASTE, supra note 217, at 53 ("With only one site to regulate, the standards and regulations were adapted to the unique characteristics of Yucca Mountain.'); The KeYstone CTR., supra note 248, at 69 (noting that the elimination of alternative sites from consideration "led to concerns that the federal government would find Yucca Mountain suitable even if it failed to meet acceptable criteria").

254. See Whipple, supra note 229.

255. See Roland M. Frye, Jr., The Current "Nuclear Renaissance" in the United States, Its Underlying Reasons, and Its Potential Pitfalls, 29 ENERGY L.J. 279, 356 (2008) ("[U]ntil the country resolves the spent fuel management issue, it will hinder the development of nuclear energy in the United States.").

256. A license denial for Yucca Mountain would not necessarily signal the end for geologic disposal. In theory, it would indicate only that Yucca Mountain is not the right site. Similarly, an approval at Yucca Mountain would represent only a temporary solution, and one useful only for this country. Unless technological advances significantly reduce waste volumes, other disposal sites still will be necessary. See THE KEYSTONE CTR., supra note 248, at 72 ("Any net expansion of U.S. nuclear power generation would require significantly greater repository capacity than currently established by law for the Yucca Mountain site."). But see Joshua Boak, Cost Slows Nuclear Plant Drive: Tab Has Doubled in Past Year as Uncertainties Rise, CHI. TRIB., May 7, 2008, § 3, available at http://archives.chicagotribune. com/2008/May/07/business/Chi-wed-nuclear-energy-debate-May07 ("If we had all this trouble over one Yucca Mountain, do we really want to have this problem over 10 [of them]?" (alteration in original) (internal quotation marks omitted)).

257. See Cotton, supra note 222, at 37 (explaining the financial pressures on the federal government); Matthew L. Wald, U.S. Decides One Nuclear Dump Is Enough, N.Y. TIMES, Nov. 7, 2008, at A1 (observing that even without additional delays, "the government will owe commercial damages to the utilities of $\$ 11$ billion or more").

258. See Energy Policy Act of 1992, Pub. L. No. 102-486, $\S 801,106$ Stat. 2776, 2921-23 (1992) (codified as amended at 42 U.S.C. $\$ 10141$ (2006)).

259. The NAS's entire discussion of the subject is as follows: "We recommend that the mean values of calculations be the basis for comparison with our recommended standards." TECHNICAL BASES, supra note 220, at 123. 
technical grounds. ${ }^{260}$ Even as administrative dialogues go, this has been no shining example of deliberative democracy.

Nevertheless, while this process may not be ideal, the EPA did at least set forth options and rationales, the ensuing dialogue affected outcomes, and the end result is a real standard. That distinguishes nuclear waste management from the other areas of environmental law, where statutes and regulations have done little to constrain probability standards and agencies typically make their choices on an ad hoc basis. That flexibility can become rather problematic if, as often happens, the agency's staff is pressured to approve plans with slim success odds. Because Yucca Mountain will be evaluated against such a probability standard, there is more transparency, ${ }^{261}$ the foundations of a public debate, ${ }^{262}$ and the possibility of some degree of accountability if inappropriate factors enter the decisionmaking. That does not mean that the numerical standard is a panacea; numbers can create a false sense of certainty, and some scientists have questioned the utility of quantitative predictions for Yucca Mountain. ${ }^{263}$ But in an otherwise highly politicized process, those requirements ensure that not just any superficially credible proposal can be approved. ${ }^{264}$

260. The EPA initially argued that the median would be less likely to be skewed by the results of harmful but improbable scenarios. However, in a probabilistic risk assessment, a Monte Carlo analysis does not give extra weight to extreme values; each individual run represents a combination of circumstances with an equal chance of occurring (if the data and assumptions are correct, which of course they never entirely are), and the mean of all of those outcomes should not disproportionately weight any individual run. See Poulter, supra note 237 , at 11 ("[B]ecause the methods provide probability distributions of exposure or risk, they avoid the problems of compounding conservative values of input variables.").

261. See Whipple, supra note 229, at 67 ("'O]ne of the most important purposes served by [DOE's modeling approach] is the disclosure of the assumptions, models, and analytic methods underlying the project staff's understanding of the repository system.").

262. In developing its 2001 rule, which the D.C. Circuit set aside, and again in its 2005 proposed rule, the EPA outlined alternative possible approaches, explained its view of their merits or weaknesses, and invited comment on those approaches; many of the resulting comments were substantive. Public Health and Environmental Radiation Protection Standards for Yucca Mountain, NV, 66 Fed. Reg. 32,091 (June 13, 2001) (codified as amended at 40 C.F.R. pt. 197); Public Health and Environmental Radiation Protection Standards for Yucca Mountain, NV, 70 Fed. Reg. 49,033-34, 49,041-46 (proposed Aug. 22, 2005) (to be codified at 40 C.F.R. pt. 197).

263. E.g., Rodney C. Ewing, Performance Assessments: Are They Necessary or Sufficient?, in UNCERTAINTY UNDERGROUND: YUCCA MOUNTAIN AND THE NATION's HIGHLEVEL NuCLEAR WASTE, supra note 217, at 81; Macfarlane, supra note 232, at 92-94 (describing objections to numeric standards).

264. See Macfarlane, supra note 232, at 87 ("[S]trong political pressure exists ... to characterize Yucca Mountain as a suitable site for the disposal of high-level nuclear waste."). 


\section{G. Climate Change}

The foregoing examples demonstrate that problems of planning uncertainty pervade first-generation environmental laws, and that those laws provide sparse and uneven guidance about how those problems should be resolved. Those laws' emphasis on planning is well documented, and commentators frequently note that environmental instabilities and uncertainties were not as well appreciated during the 1960 s and 1970s as they are now. ${ }^{265}$ But the problems are not just relics of a past age. As Congress and environmental agencies - and, in all likelihood, international bodiestake on new environmental challenges, similar issues will likely recur, and those issues will likely be particularly salient for any sort of legal response to climate change.

Even in the absence of major new federal legislation, that salience may result from new applications of older environmental laws. Climate change already has triggered threatened species listings, ${ }^{266}$ created water quality threats, ${ }^{267}$ and been a central issue in NEPA litigation. ${ }^{268}$ If a "nuclear renaissance" becomes part of a strategy to reduce greenhouse gas emissions, the plan uncertainty issues associated with nuclear waste disposal will assume greater importance. ${ }^{269}$ Perhaps most importantly, listing greenhouse gases as pollutants could trigger obligations to address greenhouse gases through the CAA's planning provisions. ${ }^{270}$ Even if the United States

265. E.g., Fine \& Owen, supra note 30, at 909-10; Tarlock, supra note 29, at 1122-23; Jonathon Baert Wiener, Beyond the Balance of Nature, 7 DUKE ENVTL. L. \& POL'Y F. 1, 2 (1996).

266. See J.B. Ruhl, Climate Change and the Endangered Species Act: Building Bridges to the No-Analog Future, 88 B.U. L. Rev. 1, 5-6 \& n.12 (2008).

267. See CTR. FOR BIOlOGICAL DIVERSITY, PETITION FOR REVISED PH WATER QUALITY Criteria Under Section 30 of the Clean Water Act, 33 U.S.C. $\$ 1314$, To Address OCEAN ACIDIFICATION (2007), http://www.biologicaldiversity.org/programs/oceans/pdfs/ section-304-petition-12-18-07.pdf.

268. E.g., Ctr. for Biological Diversity v. Nat'l Highway Traffic Safety Admin., 538 F.3d 1172, 1215-17 (9th Cir. 2008) ("The impact of greenhouse gas emissions on climate change is precisely the kind of cumulative impacts analysis that NEPA requires agencies to conduct."); see Int'l Ctr. for Tech. Assessment et al., Petition Requesting that the Council on Environmental Quality Amend Its Regulations To Clarify that Climate Change Analyses Be Included in Environmental Review Documents (Feb. 28, 2008).

269. See Frye, supra note 255, at 282-88 (describing increasing interest in nuclear power).

270. See Mass. v. EPA, 549 U.S. 497, 528-35 (2007) (holding that carbon dioxide is a "pollutant," and thus triggering the obligation, if the EPA determines that $\mathrm{CO} 2$ endangers public health or welfare, to regulate $\mathrm{CO} 2$ emissions under multiple provisions of the CAA); EPA, Proposed Endangerment and Cause or Contribute Findings for Greenhouse Gases Under Section 202(a) of the Clean Air Act, 74 Fed. Reg. 18,886 (proposed Apr. 24, 2009) (to 
relies primarily upon existing laws to address climate change, the effectiveness of its response will depend heavily upon approaches to managing planning uncertainty.

New climate change legislation is likely to repeat some of that emphasis on planning. Almost any comprehensive climate change legislation or treaty is likely to create a specific numeric target - for example, that by 2050 greenhouse gas emissions will be less than seventeen percent of 2005 levels ${ }^{271}$ - and to either directly propose or task the EPA with developing measures to achieve that goal. ${ }^{272}$ Whether the measures involve a cap and trade system, technologybased controls, carbon taxes, research and development subsidies, some other regulatory instrument, or a combination of approaches, those measures will collectively function as a plan for achieving the target, just as a SIP functions as a plan for achieving the NAAQS. That planning also will likely occur at multiple scales. Individual measures, like carbon offsetting trades, will likely function as plans within the larger plan. ${ }^{273}$

The success of these plans will not be certain. ${ }^{274}$ Economic predictions, projections of future technological development, and estimates of the enforceability of legal controls all are likely to contain significant levels of uncertainty. Even a cap and trade system, which theoretically offers the promise of a predefined emissions-reduction outcome, ${ }^{275}$ will in practice face unknowns. ${ }^{276}$ Because so many sources contribute greenhouse gas emissions, including all in the cap

be codified at 40 C.F.R. ch. 7) (issuing an endangerment finding pursuant to the parallel language of Clean Air Act section 202).

271. American Clean Energy and Security Act of 2009, H.R. 2998, 111th Cong. $\$ 702$ (1st Sess. 2009).

272. See Victor B. Flatt, Taking the Legislative Temperature: Which Federal Climate Change Legislative Proposal Is "Best"?, 102 Nw. U. L. REv. COLloQuY 123, 127-29 (2007) (describing legislative proposals); Jonathan Baert Wiener, Global Environmental Regulation: Instrument Choice in Legal Context, 108 YALE L.J. 677, 712-13 (1999) (describing the Kyoto Protocol, which uses a mandatory cap approach and leaves signatory nations to develop plans to comply with that cap).

273. See H.R. 2998, § 722(d)(1) (allowing offsets).

274. Holly Doremus \& W. Michael Hanemann, Of Babies and Bathwater: Why the Clean Air Act's Cooperative Federalism Framework Is Useful for Addressing Global Warming, 50 ARIZ. L. REV. 799, 809-16 (2008) (explaining some weaknesses of cap-andtrade approaches).

275. See Wiener, supra note 272 , at $727-34$ (contrasting cap-based and tax-based regulatory systems).

276. U.S. Gov't Accountability Office, Lessons Learned from the European Union's Emissions Trading Scheme and the Kyoto Protocol's Clean Development Mechanism 6 (2008) (noting that even after several years of implementation, the European Union's emissions trading system's "effects on emissions are uncertain"). 
and trade system may be infeasible. ${ }^{277}$ Estimating emissions from some sources or absorption from some carbon sinks-for example, from forestry or agricultural activities-also cannot be done with anything approaching perfect accuracy or precision, and overly optimistic estimates could easily thwart achievement of the cap. ${ }^{278}$ Even for sources included in the cap and trade system and amenable to precise and accurate quantification, compliance failures are always a possibility, particularly if monitoring and enforcement systems are not robust. ${ }^{279}$

Consequently, the effectiveness of any legal response to climate change will depend partly on responses to several layers of planning uncertainty. Lawmakers will need to decide not only how to address the risk that the overall plan will not obtain its targets, but also how to manage the risk that individual components of that overall strategy will not produce planned outcomes. Ideally their response will not rest solely on ex ante attempts to manage plan uncertainty; monitoring, enforcement, and adjustment also are likely to be essential. ${ }^{280}$ Other nonplanning regulatory mechanisms, like efficiency standards and incentives for technological development, can provide insurance in case planning approaches fail to achieve their goals. But some proactive management of plan uncertainty will be an essential component of a successful regulatory approach.

\section{REFORMING EXISTING APPROACHES}

The preceding section demonstrates that challenges of planning uncertainty pervade environmental law and that management of those challenges has important consequences. The issue cuts across statutes and environmental media, with significant implications wherever it arises, and will likely continue to confront Congress and agencies as they grapple with climate change and other future environmental problems. The section also demonstrates that approaches to these problems vary. But several themes emerge. First, in most contexts, legislators have not prescribed and agencies have not developed clear and systematic approaches to those problems. Statutes and regulations

277. See Flatt, supra note 272, at 136-37; Wiener, supra note 272, at 692 ("In every country, virtually every human activity directly or indirectly emits GHGs ....").

278. See Flatt, supra note 272, at 142-44.

279. See U.S. Gov't Accountability Office, supra note 276, at 7-8 (describing challenges associated with the Kyoto Protocol's Clean Development Mechanism).

280. See discussion infra Part III.C (discussing arguments in favor of adaptive management). 
provide some direction, but it generally is uneven and usually is vague. Second, where meaningful constraints do exist, lawmakers still have often taken moderately indulgent attitudes towards failure risk. Thus, while these questions are important and pervasive, legal responses have tended to be ad hoc and risk-tolerant.

Are these conclusions cause for concern? There are several reasons why one might think not. To those who think environmental laws are excessively ambitious, plans that accept increased failure risk as the price for reduced regulatory stringency might seem like desirable regulatory relief. ${ }^{281}$ To environmental laws' proponents, indulgence toward uncertain plans might seem like a pressure-release valve, allowing slippage where full implementation might galvanize political frustration and jeopardize the survival of the laws themselves. ${ }^{282}$ Legislation and generalized regulations are far from perfect, ${ }^{283}$ and ad hoc decisionmaking might ameliorate legislators' and rulemakers' worst excesses and reduce the problems inherent in applying any broadly applicable law. ${ }^{284}$ If one is skeptical, as some environmental scholars are, about the value of any ex ante prediction, attempting to enforce more stringent standards for plan certainty might seem like a quixotic exercise or an invitation to manipulate predictive models. ${ }^{285}$ Consequently, one might wonder if there will be any real differences between a system involving generally applicable probability standards and one in which agencies simply find their way on a decision-by-decision basis. Even if such differences might exist, they might not seem problematic.

There are plausible bases for all of these concerns, but in this Part I explain why existing approaches to planning uncertainty can and should be reformed. The improvements should involve developing more systematic standards for planning uncertainty; creating those standards through legislative or rule-making processes rather than

281. See, e.g., Farber, supra note 28, at 301-03 (describing the EPA's reluctance to implement programs it felt were overly strict). See generally John P. Dwyer, The Pathology of Symbolic Legislation, 17 ECOLOGY L.Q. 233 (1990) (criticizing overly ambitious laws enacted primarily for their political symbolism).

282. See, e.g., Doremus, supra note 154, at 61 (explaining the willingness of FWS and NMFS to "give up the possibility of strong protection" to preserve the ESA's political viability).

283. See generally Bruce A. Ackerman \& William T. Hassler, Clean Coaldirty AIR (1981) (describing the enactment of the 1977 Clean Air Act Amendments); Dwyer, supra note 281 .

284. See Cass R. Sunstein, Problems with Rules, 83 CAL. L. Rev. 953, 957 (1995).

285. See, e.g., ORRIN H. PILKEY \& LINDA PILKEY-JARVIS, USELESS ARTTHMETIC: WhY ENVIRONMENTAL SCIENTISTS CAN'T PREDICT THE FUTURE 22-44 (2007). 
through ad hoc adjudicative or occasional judicial decisions; and, in most circumstances, ensuring that those standards are more stringent than present approaches. I make these claims for several reasons, each explored in more detail below.

\section{A. The Trouble with Ad Hoc Resolutions}

As numerous commentators have pointed out, our system of environmental law often delegates policy choices away from policy realms and asks scientific experts to resolve hidden questions of value. ${ }^{286} \mathrm{~A}$ common consequence of that tendency is political and regulatory dysfunction. Agency scientists try to shoehorn nontechnical questions, which they may have no distinctive qualification to resolve, into technical modes of analysis. ${ }^{287}$ Important value questions fade from public view, impeding outside participation and accountability. ${ }^{288}$ Problematic outcomes may be misdiagnosed as products of bad science or flawed technical decisionmaking rather than as the results of policy choices, leading lawmakers to miss opportunities to improve the underlying legal scheme. ${ }^{289}$

Existing ad hoc approaches to setting probability standards exemplify this problem of hidden policy determinations. Those approaches can remove plan uncertainty questions - questions that raise almost pure policy issues-from traditional policy-making spheres, undermining transparency, accountability, and public and legislative understanding of environmental policy choices. While the consequences of relocating decisions will not be uniform, there are multiple reasons to expect that ad hoc decisionmaking will often produce less protective plans.

\section{Transparency}

The selection of a probability standard is clearly a policy choice. Scientific or economic research can help estimate the odds of compliance, given a certain set of planning provisions, and can help

286. See Holly Doremus, Listing Decisions Under the Endangered Species Act: Why Better Science Isn't Always Better Policy, 75 WASH. U. L.Q. 1029, 1033-35 (1997); Wagner, supra note 19, at 183-86, 205-13.

287. See Doremus, supra note 286, at 1035 ("In effect, Congress has forced the listing agencies into a 'science charade,' in which they must pretend to make nonscientific decisions entirely on the basis of science. The result is an inconsistent, incoherent listing program." (footnote omitted) (quoting Wendy E. Wagner, The Science Charade in Toxic Risk Regulation, 95 CoLUM. L. REv. 1613 (1995))).

288. See Fine \& Owen, supra note 30, at 930-34; Wagner, supra note 19, at 264-66.

289. See Wagner, supra note 19, at 258. 
explain the consequences of plan failures. But science cannot determine what plan success odds are appropriate. Those questions instead implicate nonscientific determinations about the appropriate strength of societal commitments to environmental protection.

In many contexts, those policy questions are environmentally and economically important. A probability standard demanding compliance with a statutory mandate fifty percent of the time-or, in qualitative terms, more often than not-will compel fundamentally different planning schemes than a standard requiring an eighty percent success rate, or than a standard tolerant of any plan with some possibility of success. Demanding a higher success rate means preferring extra environmental protection over errors of insufficient protection, with positive consequences for environmental quality but potentially negative consequences for compliance costs. Conversely, a standard allowing a lower success rate prioritizes avoiding perceived overregulation over avoiding noncompliance with environmental standards. ${ }^{200}$ The resulting differences in costs and environmental outcomes could be substantial..$^{291}$ Anyone who cares about balancing environmental quality against compliance costs-and most participants in environmental debates care about that balancingshould be concerned about that choice.

In the absence of statutory or regulatory probability standards, however, those choices can disappear from public view. ${ }^{292}$ With no obligation to meet a standard, planners may not discuss confidence levels at all, instead presenting their predictions without any disclosure of error ranges. SIP approval documents exemplify this problem; discerning from those documents what level of failure risk the EPA and the states have accepted is often nearly impossible. ${ }^{293}$ That opacity is not inevitable. Even before probability standards existed, NOAA Fisheries scientists provided probability estimates to fishery management councils, ${ }^{294}$ and at least a qualitative estimate is usually

290. To state a standard is not to ensure compliance, of course, but if there is any correlation between the standard and the actual plan, then a stringent probability standard will mean more protective measures, different environmental outcomes, and different costs.

291. See Figure 1.

292. See thomas O. McGarity, Reinventing Rationality: THE Role of REgUlatory ANALYSIS IN THE FEDERAL BUREAUCRACY 133 (1991) ("Former EPA Administrator Douglas Costle has noted that ' $[\mathrm{t}]$ hat which can be measured tends to receive more weight than less tangible, though perhaps more important effects which cannot be quantified."'); Fine \& Owen, supra note 30, at 930-34.

293. See discussion supra Part II.B.

294. See, e.g., NRDC v. Daley, 209 F.3d 747, 750-51 (D.C. Cir. 2000) (describing probability estimates). 
possible-but generally, it takes a requirement to spur a discussion. Consequently, outsiders may have no basis for discovering, let alone evaluating, the agency's approach to plan uncertainty. ${ }^{295}$

Nor is the problem unique to outsiders. Even internal agency personnel may not understand their agency's approach, or may deliberately avoid confronting it. Planners without technical background or knowledge may consider uncertainty management a question for the modelers, whose results they will simply and conveniently accept as firm predictions regardless of the underlying uncertainties. ${ }^{296}$ Without a probability standard signaling the need for such information, technical staff members who do understand the uncertainty choices at stake may choose not to explain them. They may fear their explanations will be misinterpreted as confessions that their work was inadequate ${ }^{297}$ or may believe, as many scientists do, that policy makers and lawyers have no interest in hearing about uncertainties. ${ }^{298}$ Again, the fisheries example illustrates that such disappearance does not always occur. But it is at least plausible to expect that the absence of a probability standard will mean an associated absence of anything more than an exceedingly general and uninformative acknowledgement of failure risk. ${ }^{299}$

Even if planners do document their approach, the absence of generalized probability standards can move the resulting discussion to a less accessible forum. While in almost any forum, regulated entities tend to participate more extensively than regulatory beneficiaries, ${ }^{300}$ legislative or rulemaking processes are somewhat more accessible to outside participants with limited funds, limited time, or limited expert

295. See supra notes 112-114 and accompanying text.

296. E.g., Fine \& Owen, supra note 30, at 930 \& n.143, 956 n.286 (describing modelers' perceptions that nontechnical policy makers had no interest in hearing about potential uncertainties); Wagner, supra note 19, at 221-57 (explaining reasons why Congress may be uninterested in learning about scientific uncertainties, or unable to do so). While Wagner focuses on Congress, much of her analysis could apply equally to politically savvy agency employees.

297. See MCGARITY, supra note 292, at 134-35 ("If analysts forthrightly confront the uncertainties inherent in their predictions and make the decisionmaker aware of the general lack of confidence with which they speak, they risk rejection."); Wagner, supra note 19, at 238-45.

298. See Fine \& Owen, supra note 30 , at 930 \& n.143, 957 n.286. In informal conversations with environmental scientists, I have often heard somewhat similar assertions, many grounded in the fallacious but seemingly widely held notion that law cannot accommodate uncertain answers from scientists.

299. See, e.g., discussion supra Part II.B (discussing air quality management).

300. Sidney A. Shapiro \& Rena Steinzor, Capture, Accountability, and Regulatory Metrics, 86 TEX. L. REv. 1741, 1751-56 (2008). 
resources. While these participants rarely have the capacity to participate in hundreds of plan-by-plan choices about uncertainty risk, particularly where understanding those choices requires technical sophistication, they are more likely to be able to weigh in if the agency sets a generalized policy through a single consolidated notice and comment rulemaking. ${ }^{301}$ Regulated interests, by contrast, often have greater financial resources and more sharply defined motivations, and are often more able to participate in diffused, ad hoc decisionmaking processes. $^{302}$

Such opacity and skewed participation create problems. Our environmental law system is premised upon widely shared notions that allowing at least the possibility of participation is democratically important, and that technocratic decisionmaking, though necessary, ought to be tempered by dialogue among nontechnical policymakers and interested members of the public. ${ }^{303}$ That system's emphasis on participation also reflects awareness that outside participants can supplement the often minimal information base and homogenous perspectives upon which agency decisionmakers rely. ${ }^{304}$ Transparency and accountability are directly connected; it is more difficult for agencies to premise plan choices on poorly reasoned rationales, or on reasons at odds with statutory directives, if their reasoning must be explained. $^{305}$ Participation and outside review also have their detractors, of course, and legal literature is filled with warnings about obstructionist participation. ${ }^{306}$ But ample experimental and anecdotal

301. See, e.g., EAGLE ET AL., supra note 55, at 34-35 (describing difficulties created by diffused fisheries decisionmaking); Lynn E. Blais \& Wendy E. Wagner, Emerging Science, Adaptive Regulation, and the Problem of Rulemaking Ruts, 86 TEX. L. REv. 1701, 1726-28 (2008) (describing greater environmental participation in the centralized, high visibility process of setting NAAQS); Fine \& Owen, supra note 30, at 951-52, 967-68 (discussing challenges faced by public participants). I also base this assertion on my own experience representing and working with public interest environmental groups.

302. See Doremus, supra note 154, at 84; Latin, supra note 81, at 1673-75; Shapiro \& Steinzor, supra note 300, at 1755 ("Regulated industries are especially likely to have disproportionate influence when regulatory proposals are of low political salience and high technological complexity.").

303. Fine \& Owen, supra note 30, at 916-19.

304. Jody Freeman \& Daniel A. Farber, Modular Environmental Regulation, 54 DUKE L.J. 795, 895 (2005); Anne E. Simon, Valuing Public Participation, 25 Ecology L.Q. 757, 760 (1999); Thomas C. Beierle \& Jerry Cayford, Environmental Decision Making: What Does Public Participation Add?, 28 ADMIN. \& REG. L. NEWS, Feb. 7, 2003, at 15-16.

305. See Motor Vehicle Mfrs. Ass'n v. State Farm Mut. Auto. Ins. Co., 463 U.S. 29, 43-44 (1983) (explaining that a flawed explanation for an agency's action is grounds for setting that action aside).

306. E.g., Freeman \& Farber, supra note 304, at 895 ("[T]he inspirational stories of breakthroughs due to stakeholder initiative are frequently enough balanced by more 
evidence, as well as common sense, suggest that integrating a wider variety of perspectives into decisionmaking processes can improve outcomes. $^{307}$ That evidence suggests that for the sake of promoting democratic and informed decisionmaking, probability standards, and the discussions they necessitate, are important.

\section{Biases and Skewed Outcomes}

A desire for transparency is an important reason to favor generalized probability standards over present ad hoc approaches, but it is not the only reason. Generalized probability standards also are likely to lead to more careful approaches to plan uncertainty. That is because systematic processes can reduce, though by no means eliminate, some of the decisionmaking biases inherent in ad hoc approaches.

\section{a. Optimism}

As both experimental and empirical evidence repeatedly indicate, people tend to approach environmental uncertainty with excessive optimism. ${ }^{308}$ Confronted with uncertain future resource availability or with unknown risk, people tend to assume the best, thinking that outcomes will likely be at the more desirable end of the range of possibilities. ${ }^{309}$ People also tend to assume that they will exercise more control than is actually likely, and thus overestimate their capacity to

depressing accounts of breakdowns, or of less than noble participation ....”); J.B. Ruhl, Regulation by Adaptive Management-Is It Possible?, 7 MINN. J.L. SCI. \& TECH. 21, 46-53 (2005) (blaming interest groups and their lawsuits for struggles implementing the ESA's HCP program); Richard B. Stewart, Madison s Nightmare, 57 U. CHI. L. REv. 335, 340-42 (1990).

307. E.g., EAGLE ET AL. supra note 55, at 2, 27 (describing problems with the absence of public interest group representatives from regional fishery management councils); Camacho, supra note 126, at 318 ("II]n HCP processes in which the applicants ... voluntarily opened up the negotiations to stakeholders, the instrumental value of such participation has been impressive.").

308. See Robert T. Clemen, Improving and Measuring the Effectiveness of Decision Analysis: Linking Decision Analysis and Behavioral Decision Research, in DeCISION MODELING AND BEHAVIOR IN COMPLEX AND UNCERTAIN ENVIRONMENTS 6 (Tamar Kugler et al. eds., 2008) ("Overconfidence is one of the most persistent biases that decision analysts face."); LEE, supra note 32, at 151 (describing the "systematic tendency to overestimate the likelihood that plans will succeed"); Barton $\mathrm{H}$. Thompson, Jr., Tragically Difficult: The Obstacles To Governing the Commons, 30 ENVTr. L. 241, 258, 264 (2000) (noting the human tendency, in contexts of uncertainty, toward "tremendous wishful thinking," and citing studies).

309. See Thompson, supra note 308, at 258-59; Eagle \& Thompson, supra note 30, at 671-72 (describing the effects of optimism upon fishery management decisions). 
produce desirable outcomes. ${ }^{310}$ Those tendencies have significant implications for plans approved in contexts of uncertainty. Planners, even if unaffected by outside pressure, will likely overestimate the effectiveness of their plans, both because they underestimate potential complications and adverse circumstances and because they overestimate their own degree of control.

Outside pressures can exacerbate such false optimism. If optimism leads to less stringent regulation or plans more permissive of resource exploitation, regulated parties are likely to be pleased. Regulatory beneficiaries may react with heightened opposition, but they typically have less capacity to engage and critique decisions, particularly if levels of plan certainty are being chosen in many different decisions rather than a few consolidated processes. ${ }^{311}$ Optimism therefore has not only psychological predispositions but also political leverage at its back. The common consequence, not surprisingly, is what a FWS scientist involved in the Pacific Northwest's spotted owl controversies once described as "considerable ... political pressure to create a plan which was an absolute minimum. That is, which had a very low probability of success and which had a minimum impact" upon regulated parties. ${ }^{312}$ Faced with such pressure, any normal person will be inclined toward the path of least resistance.

Creating generalized probability standards does not necessarily fix those problems, for agency staff may use the same rose-tinted lenses to assess a plan's probability odds that it otherwise would use in making ad hoc, standardless judgments of plan adequacy. ${ }^{313}$ But the presence of uncertainty standards can dampen optimism bias. Where a standard exists, some internal inquiry about whether the standard has been achieved becomes necessary, and that inquiry can reveal

310. See Thompson, supra note 308, at 264-65 ("[W]hen confronted by an uncertain future, most people assume that they will be able to avoid, reduce, or ameliorate future risks.").

311. See supra notes 300-302 and accompanying text.

312. Seattle Audubon Soc'y v. Evans, 771 F. Supp. 1081, 1089 (W.D. Wash.), aff'd, 952 F.2d 297 (9th Cir. 1991); see also EAGLE ET AL., supra note 55, at 1-2 ("One of the easiest ways to reduce the pain of allocating a catch, in short, is to raise the size of the catch-to the detriment of conservation."); HoUCK, supra note 191, at 84, 102-03, 143-44 (describing similar pressures upon agency staff responsible for TMDLs); Doremus, supra note 153, at 1606 (describing pressure imposed by a political appointee within the Fish and Wildlife Service).

313. See John S. Hammond ET Al., SMart Choices: A Practical Gudde To MaKING BETTER DECISIONS 204-05 (1999) (describing experimental evidence of excessive optimism in quantitative predictions). That risk is smaller, however, if researchers estimating odds are somehow separated or insulated from decisionmakers' selecting plans, so that the political pressures to make optimistic assumptions are reduced. 
excessive optimism..$^{314}$ A standard also demands an explanation, which may be subject to internal and external scrutiny. That scrutiny has the potential to highlight excessively optimistic choices, to compensate for the political pressures demanding optimistic analyses, and to deprive nontechnical decisionmakers, who might otherwise be blissfully unaware of the possibility of plan failure, of the opportunity to wash their hands of choices about planning uncertainty. ${ }^{315}$ Finally, if estimations of failure probabilities are not distorted, or only slightly distorted, by political bias, a probability standard checks the ability of planners to knowingly adopt measures likely to fail. ${ }^{316}$ If no probability standard exists, however, that question may never be asked, or may be confronted only by a select few. The contrast between water and air quality management is illustrative. ${ }^{317}$ In the former area, a statutory margin of safety requirement at least facilitates dialogue, while in the latter, issues of planning uncertainty may be considered only by a subset of agency staff. ${ }^{318}$

A generalized probability standard also creates a metric for post hoc evaluation, and thus a potential reality check on unjustified optimism. If a probability standard suggests that agencies should be highly confident that their plans will succeed, and the agency purports to be complying with that requirement, yet only fifty percent of the agency's plans actually do attain statutory goals, the agency has a clear signal that it is using flawed predictive methods. If no probability standard exists, however, neither internal nor external observers have any basis for judging whether the fifty percent failure rate indicates flaws in the predictive process or simply results from a calculated decision to weight over- and underregulation exactly equally. Internal decisionmaking flaws will more likely remain misdiagnosed and uncorrected.

314. See HolliNG ET AL., supra note 12, at 50 ("[T] $]$ he model provides a focus for communication and a point of departure."); LEE, supra note 32, at 60 ("[S]imply because putting numbers together in a model requires enough careful thought that relationships that are logically linked tend to emerge."); supra notes 261-264 and accompanying text (discussing the inquiries necessitated by the Yucca Mountain probability standards).

315. See Houck, supra note 191, at 204 (noting that "objective standards" are important to facilitate outside review); supra notes 211-215 and accompanying text (discussing the contrast between NRDC v. Muszynki and Environmental Defense Fund $v$. EPA).

316. See Houck, supra note 191, at 204.

317. See supra notes 211-215 and accompanying text.

318. See discussion supra Parts II.B, E. 


\section{b. Identifiability and Availability}

Ad hoc decisionmaking also is likely to be affected by "identifiability" or "availability" biases. Those biases also affect systematic decisionmaking, but there are likely to be differences of degree, and those differences will often favor legislative or rulemaking approaches.

The identifiability bias is a tendency to give excessive weight to interests with which we can emotionally identify and less weight to interests that, while potentially more important, inspire no such emotional link. ${ }^{319}$ The "availability" bias or heuristic is similar; it refers to a tendency to give more weight to phenomena that are cognitively "available" or "recallable" than to phenomena that seem remote, and explains why a person might have more fear of a risk associated with a powerful narrative, such as a nuclear meltdown, than a risk that seems more pedestrian. ${ }^{320}$ Scholars have invoked both to explain all sorts of tendencies, sometimes in apparently conflicting ways; according to various accounts, they explain why we have too much environmental regulation, or too little, or regulation directed to the wrong priorities. ${ }^{321}$ But there is little doubt that the tendencies do exist. ${ }^{322}$

Because different information is likely to drive generalized legislative or rulemaking processes than drive individual project- or plan-specific decisions, these biases have significant implications for decisions about forums and processes for making decisions about plan uncertainty. Once a specific plan is on the table, the bearers of regulatory burdens are likely to become readily identifiable, and their stories may seem more compelling than generalized and broadly shared concerns about environmental quality. The agency offices that write rules, by contrast, typically are accustomed to using data-set-

319. See generally Shi-Ling Hsu, The Identifiability Bias in Environmental Law, 35 FLA. ST. U. L. REV. 433 (2008). $1041-44$.

320. See HAMmOND ET AL., supra note 313, at 206-07; Sunstein, supra note 13, at

321. E.g., Hsu, supra note 319 , at 436 ("[T] he identifiability effect works a consistent bias against the cause of environmental protection ...."); Christine Jolls et al., $A$ Behavioral Approach to Law and Economics, 50 STAN. L. REV. 1471, 1518-20 (1998) (arguing that availability explains legislative overreactions to relatively minor environmental threats); Sunstein, supra note 13, at 1041-44 (arguing that the availability heuristic explains the unjustified appeal of a strict precautionary principle).

322. See Amos Tversky \& Daniel Kahneman, Availability: A Heuristic for Judging Frequency and Probability, in JUDGMENT UNDER UNCERTAINTY, HEURISTICS AND BIASES 16378 (Daniel Kahneman et al. eds., 1982) (describing experimental evidence). 
driven studies rather than individual anecdotes. ${ }^{323}$ These distinctions are muddy; anecdotes about individual circumstances have power in any sort of process, and adjudicative decisions are rarely made with complete blinders to broader trends. ${ }^{324}$ These biases also may cut the other way; when a specific plan is on the table, its environmental benefits may be more readily identifiable. ${ }^{325}$ But much of environmental law is devoted to producing generalized, long-term, dispersed gains at the expense of more focused and immediate regulatory burdens, and those regulatory burdens are likely to assume greater political force as individual planning choices bring them into sharper focus. ${ }^{326}$

\section{c. Cumulative Misperceptions}

Another problem arises from the diversity of sources contributing to many environmental problems. That diversity creates a potential collective action problem: the benefits of leniency may accrue disproportionately to individual agency decisionmakers, while the benefits of stringency will be more broadly dispersed and can therefore be easy to ignore.

Many environmental problems arise from the collective effect of many actions, some of which would individually seem inconsequential. Degradation of regional air or water quality and losses of endangered species habitat often occur incrementally, ${ }^{327}$ for example, and some emerging environmental threats, like increasing greenhouse gas concentrations, likewise arise from the accumulated consequences

323. See Craig N. Oren, Whitman v. American Trucking Associations-The Ghost of Delegation Revived ... and Exorcised, in AdMINISTRATIVE Law StoRIES 9-26 (Peter L. Strauss ed., 2006) (describing processes of setting air quality standards); MCGARITY, supra note 292, at 45-61 (describing the EPA's process of setting the ambient air quality standard for particulate matter). See generally Kenneth Culp Davis, An Approach to Problems of Evidence in the Administrative Process, 55 HaRv. L. REv. 364, 402-25 (1942).

324. For example, dramatic events like the Cuyahoga River fires and the Santa Barbara oil spill are widely credited with accelerating environmental law's development. See e.g., RichaRd J. LAZARUS, THE MAKING OF ENVIRONMENTAL LAW 58-59 (2004).

325. See, e.g., PUD No. 1 v. Wash. Dep't of Ecology, 511 U.S. 700, 735 (1994) (Thomas, J. dissenting) (worrying that parochial environmental concerns will interfere with broader energy policies).

326. See, e.g., Doremus, supra note 154, at 62 ("[F]ocused political pressures . . a are more likely to come from the regulated than from the beneficiaries of regulation."); John $\mathbf{M}$ Volkman \& Willis E. McConnaha, Through a Glass, Darkly: Columbia River Salmon, the Endangered Species Act, and Adaptive Management, 23 ENVTL. L. 1249, 1263 (1993) ("Often, the short-term economic benefits of development are obvious, while the benefits of environmental recovery are easy to discount.").

327. See Daniel C. Esty, Environmental Protection in the Information Age, 79 N.Y.U. L. Rev. 115, 196-97 (2004); Houck, supra note 191, at 4-5. 
of many smaller actions. ${ }^{328}$ If decisionmakers ignore individual actions' contributions to such larger problems, the larger problems are likely to remain unsolved. Yet ignoring these small contributions is often easy, for the link to the larger problem may seem less immediate and less apparent than the localized consequences. Even if a regulator knows a species is threatened by a local development approval, she may easily rationalize putting a few local animals at risk, forgetting that elsewhere planners may be thinking in similar ways and that the collective consequence may be extinction. ${ }^{329}$ The normal human tendency to view one's own behavior in an excessively positive light, and therefore underestimate contributions to shared problems, is likely to exacerbate that effect. ${ }^{330}$ In combination, these tendencies can lead people to mentally isolate local choices from larger environmental problems.

Those distortions can change outcomes, for often the extent of many environmental problems is controlled by multiple planning choices. Multiple consultation or permitting decisions, for example, can collectively determine the fate of an endangered species, and while the degradation allowed in each permitting decision may seem minor when viewed independently, the collective effect may be a significant reduction in species habitat. ${ }^{331}$ Regional air quality may depend upon multiple SIP amendments. ${ }^{332}$ If nuclear energy use continues, future radiation levels will likely depend upon multiple permitting processes like that currently underway for Yucca Mountain. ${ }^{333}$ Not all planning decisions create this threat; if the geographic and temporal scale of a plan matches the geographic and temporal scale of an environmental problem, then the plan can serve as a mechanism for comprehensively addressing contributing sources, and can be an antidote rather than a

328. See Ctr. for Biological Diversity v. Nat'l Highway Traffic Safety Admin., 538 F.3d 1172, 1215-17 (9th Cir. 2008).

329. See Shilling, supra note 132, at 1662 ("Even when recovery plans have been developed, goals have often been set below the existing population size at the time of listing, a strategy that has provoked the admonition that species are being 'managed for extinction."').

330. See Thompson, supra note 308 , at $260-61$ (summarizing research demonstrating a tendency to underestimate one's own contribution to resource degradation).

331. See Rohlf, supra note 140, at 115 ("The Services commonly approve project after project that have significant impacts on threatened and endangered species and their habitats, pushing these organisms incrementally closer to extinction."); Shilling, supra note 132, at 1662 ("The cumulative effect of [the HCP] process across the landscape on survival of endangered species has not been adequately addressed ....").

332. Air quality in East Coast states, for example, depends not only on in-state plans but also on upwind states' emissions.

333. SeeTHE KeYSTONE CTR., supra note 248 , at 72. 
contributor to misunderstanding of cumulative impacts. But many plans have scopes smaller or temporally shorter than the scale of the underlying problem.

In those situations, ad hoc decisionmaking is more likely than systematic approaches to produce lax approaches to plan uncertainty. Systematic approaches tend to be driven to a somewhat greater extent by collective consequences; when the EPA develops national air quality standards, for example, its focus is somewhat more likely to be the desired national outcome, rather than regulatory costs unique to a specific company or individual. ${ }^{334}$ And when one focuses on those broader consequences, and thus is considering the collective effect of many plans, some percentage of which are likely to fail, it is harder to write off chronic high failure risk on the assumption that some other plan will pick up the slack. ${ }^{335}$ Additionally, even if local planners realize their plan's potential contribution to a larger problem, they may gain little, in the absence of a generalized probability standard, from taking steps to limit that contribution. ${ }^{336}$ The political penalties of adopting a stringent plan will accrue disproportionately and immediately to those specific planners, while the benefits will likely be more temporally or spatially dispersed, and may prove negligible if other planning offices are unwilling to face similar controversy. ${ }^{337}$ With each decision, planners therefore have incentives to plan leniently, creating local benefits while courting failure risks that others in different places or at different times will share. A systematic standard, by contrast, provides an opportunity for a collectively developed, mutually coercive solution to this collective action problem.

334. For case studies of the EPA's process of setting air quality standards, see MCGARITY, supra note 292, at 45-61; Oren, supra note 323.

335. EPA's final safety standard for Yucca Mountain exemplifies this danger. Traditional nuclear safety standards adhere to an "apportionment" principle, which requires site-specific standards to be sufficiently low to allow for radiation from other sources. TECHNICAL BASES, supra note 220, at 40-41. In its Yucca Mountain standard, however, the EPA disregarded the need for other sources and decided to allocate the entire standard to Yucca Mountain alone. See Public Health and Environmental Protection Radiation Standards for Yucca Mountain, NV, 73 Fed. Reg. 61,256, 61,266 (Oct. 15, 2008) (to be codified at 40 C.F.R. pt. 197).

336. See generally William W. Buzbee, Recognizing the Regulatory Commons: A Theory of Regulatory Gaps, 89 lowA L. REV 1, 32-33 (2003) (discussing collective action problems leading to underregulation).

337. Even if the same planners will reap the short-term benefits and long-term costs of leniency, human psychology still can create distorting effects. "Bounded willpower" and "hyperbolic discounting" can still lead planners to favor short-term conflict avoidance. See generally Jolls et al., supra note 321, at 1479, 1539. 


\section{d. Agency Competence and Culture}

The foregoing discussion suggests several reasons why ad hoc decisions will tend to produce more risk-tolerant outcomes. However, other factors can complicate the analysis. Most importantly, ad hoc decisionmaking can relocate responsibilities from Congress to agencies, from agencies' political appointees to their career staff, or from one internal agency office to another. Sometimes, in spite of the tendencies described above, those shifts may produce more cautious decisions.

Most government agencies are culturally heterogeneous. Political appointees in management positions, whose goals are likely to reflect the priorities of the current administration, may emphasize different goals than agency staff, who may have joined the agency partly because of a sense of identification with its traditional mission. ${ }^{338}$ Among agency staff, different professional backgrounds may lead to different priorities. ${ }^{339}$ Even among similarly situated administrative bodies, differences in staffing, tradition, or individual personalities may lead to disparate approaches. Different fishery management councils, for example, have taken markedly disparate approaches to fishery regulation..$^{340}$

Because of those heterogeneities, any categorical assertion about the effects of displacing ad hoc decisionmaking with systematic rulemaking processes will be at least partly wrong. Sometimes such relocation will produce more protective outcomes, but not always; it depends on the perspective of the involved appointees and staff, and the extent to which technical staff are insulated from, or resistant to, pressure from regulated groups. Likewise, sometimes creating specific probability standards will empower agency staff interested in furthering the agency's environmental protection mission, for those standards will provide staff with a bulwark against outside pressure, ${ }^{341}$ but, again, not always. While there are reasons to expect that substituting more systematic decisionmaking approaches for the

338. Internal disputes within the Bush Administration have repeatedly revealed this trend. See, e.g., James Gerstenzang \& Janet Wilson, White House Puts Warming Threats on $B A C K B U R N E R$, L.A. TIMES, July 12,2008 , at Al.

339. See, e.g., MCGARITY, supra note 292, at 6-16 (describing differences between "program office" and "policy office" cultures). This disparity can be particularly salient where multiple agencies work on the same problem.

340. EAGLE ET AL., supra note 55, at 19 (describing the North Pacific Council).

341. For example, in one interview, EPA staff told me they would have a hard time demanding significant margins of error in SIPs without some guidance or regulation to cite as authority. Telephone Interview with Doris Lo \& Sarvy Mahdavi, supra note 108. 
present ad hoc approach will often produce more cautious decisionmaking, other contextual factors ensure the existence of some exceptions.

\section{B. The Benefits of High Probability Standards}

Even if ad hoc decisions will often produce lenient probability standards, that raises another question: is there anything wrong with such lax standards? Some plausible justifications for lax approaches are readily apparent, for high assurance levels are not cost free. To require an eighty percent chance of plan success means requiring that nearly eighty percent of plans impose more regulatory constraint than will turn out, in hindsight, to be necessary to achieve the statutory goal. Such additional protection can create social and economic costs, and for that reason, many environmental decisionmakers strive to avoid providing more environmental protection than necessary. ${ }^{342}$ In taking this approach, they are encouraged by regulated parties willing to use politics and litigation to protest perceived overregulation, by a judiciary often hostile to regulatory governance, ${ }^{343}$ and, sometimes, by legal-academic skepticism of the wisdom of environmental law's constraints. $^{344}$ A crucial premise - sometimes implicit and in some influential scholarship, sometimes stated fairly clearly —of much of this opposition is that overregulation is every bit as problematic as underregulation, and that both should be equally disfavored. ${ }^{345}$ Given such a framing, a moderately lenient plan uncertainty standard, like the fifty-one percent chance standard adopted in Daley, might seem not just tolerable, but optimal. Nevertheless, as I explain below, there are significant problems with this view, even if one is agnostic about whether standards for environmental outcomes are overprotective or underprotective.

A system that errs toward underprotective plans is inherently unstable. $^{346}$ If a plan fails to achieve the statutory goal, replacement

342. See, e.g., Dave Owen, Law, Environmental Dynamism, Reliability: The Rise and Fall of CALFED, 37 ENVTL. L. 1145, 1154-55 (2007); Rohlf, supra note 140, at 141-42 (describing the Department of the Interior's policy of allocating the "cushion" to endangered species-impacting projects up to the point of jeopardy).

343. See Thomas O. McGarity, The Courts and the Ossification of Rulemaking: $A$ Response to Professor Seidenfeld, 75 TEX. L. REv. 525, 530 (1997).

344. See Buzbee, supra note 336, at 4, 38-44 ("Theories of overregulation abound.").

345. See, e.g., Ackerman \& Stewart, supra note 41, at 1333-40; Cass R. Sunstein, Administrative Substance, 1991 DUKE L.J. 607, 627-31. Both articles describe regulatory approaches that produce more protection than necessary to attain compliance as inappropriately inefficient.

346. See generally Owen, supra note 342 . 
will probably be a legal necessity. ${ }^{347}$ The replacement process will likely be burdensome; environmental planning processes often last years and require thousands of hours of time. ${ }^{348}$ It also can be personally and politically costly, for a series of plan failures can exacerbate frustrations among agency staff and distrust among stakeholders. ${ }^{349}$ Failure also creates an unpredictable climate for regulated entities, for each new plan is likely to intensify regulatory constraints, undermining private investments made in reliance on the original planning scheme. That same dynamic can ossify plans, even if change is environmentally necessary; regulated groups are likely to resist changes if they already have made accommodations they thought were sufficient to achieve compliance. ${ }^{350}$ Consequently, when more protective plans finally do go into effect, all room for regulatory flexibility may have disappeared, and the new constraints may be drastic. ${ }^{351}$ They may also be permanent; because of persistent plan failures, some industries, like logging in the Pacific Northwest or cod fishing in the Northeast, may never again approach their former scale. A regulatory process marked by a high risk of plan failure, in short, will lead to pervasive governmental dysfunction, and the economic or political benefits of developing more lenient plans may be ephemeral and unreliable.

Less instability, if any, should result from erring toward additional protection. Notwithstanding the strong preferences of many regulated entities, there generally is nothing illegal about regulatory limitations that turn out, in hindsight, to be more cautious than necessary. ${ }^{352}$ No law, for example, outlaws plans that produce air slightly cleaner than the NAAQS or species abundance exceeding the goals of the ESA.

347. Not all plan failures necessitate new plans, of course. Even if mitigation measures used to facilitate NEPA compliance fail to fulfill the statutory goal, no consequence is likely, and some plan failures-for example, those associated with nuclear waste disposal-may not be correctable at all. See discussion supra Parts II.C-D.

348. See, e.g., Fine \& Owen, supra note 30, at 949-58 (describing the process of preparing a SIP).

349. E.g., Owen, supra note 342, at 1149-52, 1204 (describing the loss of agency credibility and increasing litigation resulting from the failure of the CALFED plan).

350. See generally Buzbee, supra note 336, at 33-35 (explaining incentives for preserving regulatory status quos).

351. See, e.g., EAGLE ET AL., supra note 55, at 19 (describing a complete closure of the Pacific rockfish fishery); Doremus, supra note 154, at 59-60 (describing the consequences of failed measures to protect the Northern Spotted Owl); Houck, supra note 71, at 946-47 (describing severe declines in fishery populations and their economic consequences); Owen, supra note 342, at 1202-03 (describing "drastic measures" imposed as the CALFED plan collapsed).

352. See Owen, supra note 342, at 1154-55, 1160-61. 
While regulated parties may prefer the least constraining regulatory scheme that might work, few statutes demand that those preferences be fulfilled..$^{333}$ A plan that provides more environmental benefit than turns out, in hindsight, to be necessary therefore does need not be replaced, and if it is replaced or updated, the changes will likely occur at the convenience of the agency, not under the pressure of a judicial injunction. ${ }^{354}$ Private parties may be somewhat more constrained than they would prefer, but their constraints at least will be stable. ${ }^{355}$

In addition to being a means to stable regulatory schemes, environmentally protective probability standards serve another important goal: legal compliance is an important end in itself. We value lawful conduct as an independent good-as the foundation of societal stability and as an indication of respect for the social contracts and legislative choices of a democratic society-not just as a means to promote the correct balance of economic and environmental harms. Plan failure therefore is not a problem just because legal noncompliance is inconvenient, but also because noncompliance undermines our governance system. The fact that plan failure produces unlawful outcomes therefore ought to weigh against planning systems with high failure risk.

None of the foregoing discussion means that certainty of success should be the usual standard. Demanding certainty may compel plans that prevent regulated entities from acting at all. ${ }^{356}$ If the regulated activity produces societal benefits, and reasonable alternative ways of producing those benefits do not exist, such an absolute prohibition makes little sense. A one-size-fits-all standard also is not appropriate, for some of the factors that should influence probability standards will vary by context. ${ }^{357}$ But there are fundamental problems with a system

353. The Toxic Substances Control Act, which requires EPA to regulate "to the extent necessary to protect adequately against such risk using the least burdensome requirements," might be the rare exception to this general rule, but even that language should allow agencies some discretion where EPA is not certain how much protection will be adequate. See 15 U.S.C. § 2605(a) (2006).

354. See generally Dave Owen, Legal Constraints, Environmental Variability, and the Limits of Innovative Environmental Governance, ENVTL. SCI. \& POL'Y (2008) (describing the injunctions that effectively ended the CALFED program).

355. See Owen, supra note 342, at 1162-66.

356. See Sunstein, supra note 13, at 1004 . Sometimes prohibiting all activity is appropriate; if the benefits produced by the regulated activity are minimal or the potential costs of noncompliance are exceedingly high, a prohibitively strict probability standard makes sense.

357. For example, a lower probability standard may make sense where the cumulative effects of errors of over- and underprotection are likely to cancel out, where particularly 
in which plans with a coin toss chance of success, or worse, are generally deemed legally adequate, for such an approach amounts to systemic indulgence of legal noncompliance and regulatory dysfunction. Agencies ought to be more confident that their plans will work.

\section{Ex Ante, Ex Post, and the Choice of Reform Approaches}

This Article has argued that problems of planning uncertainty pervade environmental law and that existing approaches to those problems are flawed. A skeptic might concede those points yet wonder if the proposed reforms offer a somewhat passé fix. Those reforms would increase the centralization of agency decisionmaking, and they also focus on improving predictive decisionmaking. That approach might appear to fall on the wrong side of some of the key dichotomies that environmental law scholars have set up over the last twenty years, particularly in much of the literature addressing adaptive management ${ }^{38}$ and some related work more broadly addressing "new governance" theories. ${ }^{359}$ That literature also emphasizes the uncertainties inherent in environmental management. But the common response has been skepticism of ex ante predictions and centralized approaches and a preference for monitoring and adjustment mechanisms designed to correct problems once they occur. ${ }^{360}$ I therefore close by explaining why the reforms I propose have merit.

robust measures for correcting plan failures exist, or where the costs of even moderate levels of excess protection are completely disproportionate to the benefits.

358. "Adaptive management" has taken on a range of meanings, and agency managers implementing "adaptive" approaches are sometimes doing things that the original academic proponents of adaptive management would probably condemn. See Doremus, supra note 154 , at 52-53 ("Beyond the most general level, however, there is no consensus on what adaptive management requires."); Bradley C. Karkkainen, Panarchy and Adaptive Change: Around the Loop and Back Again, 7 MINN. J.L. SCI. \& TECH. 59, 69-73 (2005).

359. See, e.g., Dorf \& Sabel, supra note 46, at 286-88 (advocating both adaptive learning and decentralized decisionmaking, in which "[t]he chief role of Congress ... would be to authorize and finance experimental reform by states and other subnational jurisdictions"). For a summary discussion of this literature, see Annecoos Wiersema, $A$ Train Without Tracks: Rethinking the Place of Law and Goals in Environmental and Natural Resources Law, 38 ENVTL. L. 1239, 1241-43 (2008).

360. See, e.g., Karkkainen, supra note 168, at 907-08 (arguing for a shift "from the uncertain and speculative realm of comprehensive ex ante prediction to the pragmatic empiricism of observation, measurement, and verification," which will "situate decisionmaking on a firmer pragmatic and empirically grounded footing"); J.B. Ruhl, Taking Adaptive Management Seriously: A Case Study of the Endangered Species Act, 52 U. KAN. L. REV. 1249, 1252, 1263 (2004) ("This 'front end/back end' distinction captures the essence of adaptive management ...."). 
The movement toward adaptive management grew out of the realization, first articulated by ecologists ${ }^{361}$ and then widely adopted by many other environmental scholars, that all environmental policies are necessarily experimental. ${ }^{362}$ Because of environmental uncertainties, human uncertainties, and complex system dynamics and feedback loops, scholars have widely concluded that no matter how hard we try to improve our predictive capacities, all environmental policies amount to tentative hypotheses. ${ }^{363}$ Drawing upon those insights, commentators have proposed that environmental managers should devote more attention to ongoing monitoring, that environmental decisionmakers should build flexibility into institutional structures, and that policies should be treated as tentative and subject to adjustment. ${ }^{364}$

So far, little contradiction should appear between these principles and the reforms I have advocated. Nothing in this Article undercuts arguments for postdecisional monitoring and adjustment. A probability standard would not eliminate plan failures; we need probability standards precisely because some predictive errors are unavoidable. Indeed, the errors will come in layers. The same uncertainties that prevent environmental managers from predicting outcomes with certainty also often preclude precise and accurate assessment of the odds of outcomes. ${ }^{365}$ Probability standards therefore will not preclude unexpected outcomes, and monitoring and adaptation will remain important. A well designed probability standard also ought to help adaptive management succeed. The point of a probability standard is to reduce the frequency and extent of required adjustments; even if all policies represent hypotheses, a probability standard should help make those hypotheses, in the aggregate, more accurate. The consequence should be to make adaptation more

361. See generally HoLLING ET AL., supra note 12 .

362. For good summaries of the evolution of adaptive management ideas, see Bradley C. Karkkainen, Adaptive Ecosystem Management and Regulatory Penalty Defaults: Toward a Bounded Pragmatism, 87 MINN. L. REv. 943, 948-56 (2003), and Angelo, supra note 29, at 1546-62.

363. See LEE, supra note 32, at 9 ("[P]olicies are experiments; learn from them."); Karkkainen, supra note 358, at 59-60.

364. See, e.g., FARBER, supra note 29, at 179-98; HOLLING ET AL., supra note 12, at 133, 136-37; LEE, supra note 32, at 138-39; Karkkainen, supra note 168, at 45-46; A. Dan Tarlock, Slouching Toward Eden: The Eco-Pragmatic Challenges of Ecosystem Revival, 87 MINN. L. REV. 1173, 1180 (2003); Wiersema, supra note 359, at 1250. These sources represent a limited sampling; the adaptive management literature is extensive.

365. For that reason, I would not suggest that any court should ever reject an agency's attempt to comply with a probability standard just because the agency has candidly admitted that its estimates of probabilities are subject to significant uncertainty. 
feasible, for smaller and less frequent adaptive changes ought to be easier to implement. ${ }^{366}$

Some of the adaptive management literature, however, seems to imply not just that back-end corrective measures will be necessary, but also that centralized efforts to improve ex ante decisionmaking are misguided. ${ }^{367}$ And some agency efforts at implementing adaptive management seem to reflect a disdain for ex ante attempts to avoid plan failure; agencies, particularly when implementing the ESA, have sometimes adopted highly optimistic approaches to plan uncertainty, apparently discounting ex ante caution because future adaptations hopefully will correct any problems that occur. ${ }^{368}$ These trends spring from different roots-many of the academic critics are concerned with the tendency of predictions to be speculative, malleable, and falsely precise, ${ }^{369}$ while the agencies sometimes seem more concerned with "using the promise of adaptive management to avoid politically tough decisions ${ }^{9370}$ - but the endpoint is the same.

But while healthy skepticism about predictive capacities is appropriate, discounting any possibility for front-end reform is problematic. Initially, one asserted basis for this skepticism-the view that environmental planners cannot predict the future at all, so there is little sense trying-overstates the case. ${ }^{371}$ Environmental managers do have some real expertise, and the enormous collective effort devoted to understanding environmental systems and developing simulation tools does allow some predictions to be made with confidence. ${ }^{372}$ Even where multiple uncertainties affect predictions, planners can often rely on statistical techniques and experienced-based judgment to estimate

366. See generally Owen, supra note 354 (explaining traditional obstacles to implementing adaptive management).

367. PILKEY \& PILKEY-JARVIS, supra note 285, at 63 (advocating "adaptive staging" as an alternative to predictive approaches); Ruhl, supra note 306 , at 35 (describing "predecisional activity" as counterproductive "foreplay"); see sources cited supra note 360.

368. See Camacho, supra note 126, at 331 (describing FWS and NMFS' use of adaptive management "in HCPs that otherwise would not qualify for an ITP because the risk to the species of granting the permit is too high"); Doremus, supra note 154, at 69-77 (describing adaptive management in ESA implementation); Owen, supra note 354, at 3 (describing the approach taken by the CALFED program).

369. See, e.g., PlLKEY \& PILKEY-JARVIS, supra note 285, at 19-20. Many of those criticisms derive from experiences with cost-benefit analyses and risk assessment. See, e.g., FARBER, supra note 29, at 165-69 (describing some of the challenges of risk assessment and cost-benefit analysis).

370. See Doremus, supra note 154, at 73.

371. See PILKEY \& PILKEY-JARVIS, supra note 285, at 204.

372. See, e.g., Working Group 1 OF the INTERgovernmental PaNel on Climate CHANGE, SUMMARY FOR POLICYMAKERS 12-17 (2007) (predicting the likelihood of future outcomes); HOLLING ET AL., supra note 12, at 6 (explaining the value of ecological models). 
uncertainties and consider their implications. ${ }^{373}$ Obviously significant uncertainties remain, sometimes recognized and sometimes not, and models can either be manipulated or simply indeterminate..$^{374}$ But there also are plenty of circumstances-climate change modeling is an important example-where predictive methods have proven indispensible. ${ }^{375}$ To suggest that environmental planners are simply blind to the future, and cannot improve their plans' odds of success, is much too pessimistic.

Additionally, as flawed as predictive approaches may be, there is no choice but to use them because postdecisional adaptive management usually offers only a limited cure. ${ }^{376}$ In many circumstances, the costs of meaningful adaptation will be prohibitive; adjusting a major infrastructure project may be impossible. Even where it is theoretically possible, adaptive management requires a lot of information, but most environmental agencies have limited resources available for research and monitoring. ${ }^{37}$ Against a background of natural variation and multiple potential causes, attributing environmental outcomes to particular causes can require long-term studies, and there also may be significant lags between the time when adjustment must occur, if the program is to be successful, and the availability of sufficient data to justify a course correction. ${ }^{378}$ Ongoing adjustment also may be institutionally and psychologically challenging, for people in general and governmental institutions in particular are not typically predisposed to midcourse correction or skeptical self-examination. ${ }^{379}$

373. See generally Poulter, supra note 237 (describing Monte Carlo and sensitivity analyses).

374. See, e.g., Pilkey \& PilkeY-Jarvis, supra note 285 (chronicling inaccurate predictions).

375. See Daniel A. Farber, Modeling Climate Change and Its Impacts: Law, Policy, and Science, 86 TEX. L. REV. 1655, 1658-67 (2008).

376. See Doremus, supra note 154, at 51-52 ("Adaptive management is essential to the ultimate success of this new age of environmental restoration. But it runs counter to human nature and the current structure of our management institutions."); Volkman \& McConnaha, supra note 326, at 1261-62 (describing multiple challenges); Owen, supra note 354 , at 3 (describing challenges in context of CALFED).

377. See Doremus, supra note 133, at 417-19.

378. See, e.g., Wiersema, supra note 359, at 1278-79 (discussing how Chesapeake Bay managers were pressured to respond to short-term data on crab populations before they had sufficient time to determine what those data meant).

379. See HAMMOND ET AL., supra note 313, at 193-200 (1999) (describing how status quo biases, sunk costs, and tendencies to overvalue confirming evidence tend to skew decisions); MCGARITY, supra note 292, at 137 (quoting an EPA analyst who asserted, "How is my career going to be advanced by doing a study that shows that three years ago the agency made a wrong prediction? It is not in my best interest." (internal quotation marks omitted)); 
Adaptive management also can marginalize participants who otherwise might effectively advocate for such corrections. Adaptive decisionmaking necessarily means temporally diffuse decisionmaking; continuing adjustment requires multiple decision points. That diffusion limits participation by stakeholders, like political leaders or environmental nonprofit groups, with limited time or financial resources. $^{380}$ But the leverage exerted by those outsiders is often crucial to the success of any environmental program, because their advocacy is often the necessary prerequisite to agencies taking environmentally protective steps, or, more fundamentally, to moving those agencies beyond familiar, comfortable habits that happen to be incompatible with the mandates of environmental laws. ${ }^{381}$ The record of adaptive management programs suggests that these theoretical concerns have ample bases in reality. From endangered species protection to ecosystem restoration, stories of adaptive management gone wrong, or gone nowhere, abound. ${ }^{382}$

To say that adaptive management approaches face significant challenges is not to say that adaptive management should not be attempted. An approach entirely predicated on predictive decisions, with little follow-up monitoring or potential for monitoring, offers a nearly blank check to wishful thinking. Nor are all adaptive management programs equally limited; there may be ways to construct more successful adaptive programs. ${ }^{383}$ But environmental managers

Doremus, supra note 154, at 55-56 ("Decisionmakers are likely to see equivocal evidence as confirming their preexisting management biases.").

380. See Doremus, supra note 154, at 81 ("The increasing decentralization of ESA decisionmaking, particularly through the HCP process, makes it even more difficult for these diffuse interests to play an effective role."); discussion supra notes 300-303 and accompanying text.

381. Many major environmental reform efforts begin with nonprofit groups' lawsuits. See Doremus, supra note 154, at 65-66 (describing the importance of citizen suits to ESA implementation); Owen, supra note 354, at 2 (describing the outset of the CALFED process). See generally Charles F. Sabel \& William H. Simon, Destabilization Rights: How Public Law Litigation Succeeds, 117 HARV. L. REV. 1015, 1020 (2004) (describing the potential for litigation 'to destabilize the parties' pre-litigation expectations through political, cognitive, and psychological effects that widen the possibilities of experimentalist collaboration").

382. Camacho, supra note 126, at 324-44; Karkkainen, supra note 358, at 61 ("Even the most well-funded and technically sophisticated ecosystem management efforts ... are still struggling, often awkwardly and uncertainly, to integrate adaptive management principles.").

383. See Doremus, supra note 154 , at $81-86$ (explaining the importance of transparency, public participation, and insulation from project-specific pressures); Karkkainen, supra note 362 , at $948-56$ (suggesting combining adaptive management approaches with penalty default systems); Owen, supra note 354, at 5 (arguing that adjustment will be easier if managers are initially cautious in allocating resources to consumptive use). 
and legal theorists ought to retain a healthy awareness of the limitations of adaptive management programs, which are likely to struggle whenever asked to produce significant adjustment in a timely manner. ${ }^{384}$ Initial decisions are still crucially important, and even if perfecting predictions is impossible, striving to proactively manage error remains a worthwhile goal.

\section{CONCLUSION}

In recent decades, much of environmental law scholarship has considered the challenges of achieving environmental improvements in contexts of uncertainty. We understand now, to a much greater extent than we did when Congress drafted most major environmental statutes, that uncertainty pervades environmental policy and that addressing those uncertainties is imperative if our legal approaches are to succeed. ${ }^{385}$ But identifying that broader problem still leaves difficult questions to be resolved: how exactly does our traditional environmental system fail to address these uncertainties, and how might we address such failings?

This Article has identified an important way in which our existing environmental laws poorly address those uncertainties. Despite the near ubiquity of systems that establish legal standards and require plans to achieve those standards, and despite the fact that planners are almost always uncertain about whether their plans will succeed, existing statutes and regulations create only a patchwork response to uncertainties about plan success. That patchwork is not uniformly problematic; in some contexts, meaningful guidance exists. But in general, most statutes and regulations leave the development of probability standards to ad hoc, nontransparent decisionmaking processes and allow widespread indulgence of plan failure. Neither tendency is desirable, and both can be reformed. By promoting more systematic and transparent confrontations with the uncertainties inherent in environmental planning, and by requiring somewhat more cautious approaches to management of those uncertainties, probability standards could reduce the persistent gaps between written environmental standards and actual performance.

384. See Owen, supra note 354 , at 6-7 (describing struggle in the context of CALFED).

385. See discussion supra note 29 and accompanying text. 
